Article

\title{
Insights into the Structural Requirements of Potent Brassinosteroids as Vegetable Growth Promoters Using Second-Internode Elongation as Biological Activity: CoMFA and CoMSIA Studies
}

\author{
Karoll Ferrer-Pertuz ${ }^{1,2}$, Luis Espinoza ${ }^{1, *}$ (iD and Jaime Mella ${ }^{2,3, *}$ \\ 1 Departamento de Química, Universidad Técnica Federico Santa María, Av. España No. 1680, \\ Valparaíso 2340000, Chile; karoll.ferrer.14@sansano.usm.cl \\ 2 Instituto de Química y Bioquímica, Facultad de Ciencias, Universidad de Valparaíso, Casilla 5030, \\ Avda. Gran Bretaña 1111, Playa Ancha, Valparaíso 2360102, Chile \\ 3 Centro de Investigación Farmacopea Chilena (CIFAR), Universidad de Valparaíso, Casilla 5030, \\ Avda. Gran Bretaña 1111, Playa Ancha, Valparaíso 2360102, Chile \\ * Correspondence: luis.espinozac@usm.cl (L.E.); jaime.mella@uv.cl (J.M.); Tel.: +56-32-250-8067 (J.M.)
}

Received: 30 November 2017; Accepted: 14 December 2017; Published: 17 December 2017

\begin{abstract}
In the present study, we have employed the ligand-based drug design technique, 3D-QSAR, through a comparative molecular field analysis (CoMFA) and a comparative molecular similarity indices analysis (COMSIA) to determine the key factors for the plant growth promoting activity of brassinosteroids reported in literature, using the bean second-internode bioassay measured on two groups of compounds with different molar concentrations. This is the first 3D-QSAR study using the second internode elongation as biological activity. These results provide useful ideas for the design of new molecules, which could be explored in the future to identify novel vegetable growth promoters with similar or greater biological activity than natural brassinosteroids. The reliability of this study was supported by the robust statistical parameters obtained from CoMFA (Model A, $\mathrm{r}^{2}$ pred $=0.751$; Model B, $\mathrm{r}^{2}$ pred $=0.770$ ) and CoMSIA (Model A, $\mathrm{r}^{2}$ pred $=0.946 ;$ Model B, $\mathrm{r}^{2}$ pred $=0.923$ ) analysis.
\end{abstract}

Keywords: brassinosteroids; bean second-internode; 3D-QSAR; CoMFA; CoMSIA; plant steroids; vegetable growth promoters

\section{Introduction}

Brassinosteroids (BRs) represent a group of polyhydroxylated plant steroid hormones that regulate plant growth and differentiation throughout their life cycle [1], and also mediate the environmental responses in plants [2]. These steroids include more than 70 structurally and functionally related compounds [3] with a common $5 \alpha$-cholestane skeleton, which have been found at very low concentrations in all organs from a wide range of higher and lower plant species, with C28-BRs (i.e., castasterone (CS), brassinolide (BL)) and C27-BRs (i.e., 28-norcasthasterone) being the most abundant and extensively present in nature [4] (Figure 1). Up to now, 65 free brassinosteroid and 5 brassinosteroid conjugates have been detected and characterized [5]. 


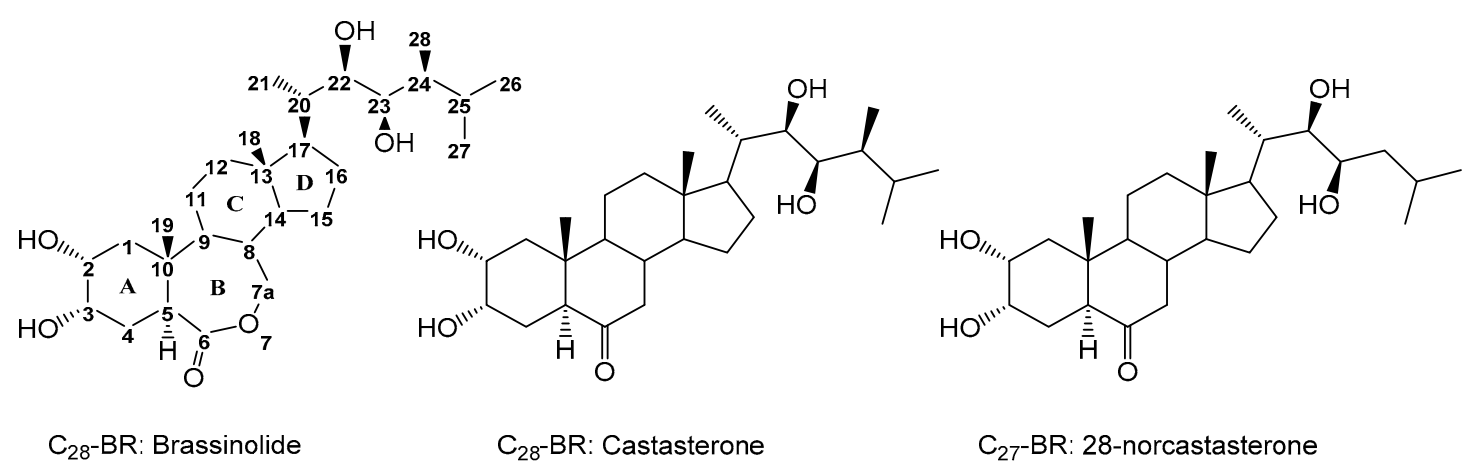

Figure 1. Brassinolide and other important natural occurring brassinosteroids.

Further work has demonstrated that BRs have a promising potential use in agriculture, since they do not only induce stem elongation, but also improve biomass formation and total crop yield, being a type of non-toxic and environmentally friendly hormone [6,7]. Moreover, BRs are recognized for their ability to stimulate growth in plants subjected to even unsuitable conditions, such as low and high temperature, excess heavy metals, salinity, water stress, drought, herbicidal injury, and pathogen attack $[5,8,9]$, thus playing a significant role in helping the plant to overcome environmental stress.

BRs have attracted considerable interest because of the notable biological effects from their exogenous application at lower than micromolar concentrations. However, the low abundance of BRs in plant sources, and their costly and difficult synthesis have stimulated several workers to search for more accessible and bioactive analogues [10,11].

The most commonly used tests for evaluating the bioactivity of brassinosteroids are the bean second-internode bioassay (BSIB) and the rice lamina inclination test (RLIT) [12]. Although different studies have recognized some essential structural characteristics for high bioactivity in brassinosteroids, subsequent research has revealed that the relative activities of brassinosteroids vary in some extent with the type of bioassay used [13], and with the dosage range in a given type of assay [14], results are not always comparable, thus, comparison of data must be taken with caution.

Some attempts to understand the structure-activity relationships (SAR) of brassinosteroids have been done by several groups. The first qualitative SAR was performed by Takatsuto et al. in a series of 21 brassinosteroids [15]. Brosa et al. performed a 2D-QSAR and a Grid map study in a small series of 15 compounds [16,17]. The same group explored the SAR through calculation of the molecular electrostatic potential of the compounds [18,19]. From the discovery of the crystal structure of the BR receptor [20,21], studies with docking technique have been performed [3]. Despite these efforts, it should be noted that, to this date, a study based on 3D-QSAR analysis using the bean second-internode bioassay is not available yet. In this sense, the aim of our study is related to generating a model with high ability for predicting the activity of new analogs and providing suggestions for the design of new potent plant growth regulators with the best synthetic cost-bioactivity relationship in order to improve the benefits of these hormones in agriculture. A comparative molecular field analysis (CoMFA) and Comparative Molecular Similarity Indices Analysis (CoMSIA) approach on two groups of brassinosteroids using bean second-internode bioassay at different concentrations has been employed to achieve this aim.

\section{Results}

\subsection{Statistical Results of Comparative Molecular Field Analysis (CoMFA) and Comparative Molecular Similarity Indices Analysis (CoMSIA)}

The statistical parameters supporting all possible field combinations of CoMFA and CoMSIA models were listed in Tables 1 and 2, respectively. The best models were used to predict the plant growth promoting activity for the BRs of the test set, the scattered plots between actual and predicted 
values for the best CoMFA and CoMSIA models of both training set and test set are shown in Figures 2 and 3. In addition, Tables 3 and 4 show the biological activity ( $\mathrm{pE}$ values) for training and test set. Residual values are also reported for each compound. All the residual values were found below \pm 0.4 within a tolerable error range.

Table 1. Summary of results from comparative molecular field analysis (CoMFA) and Comparative Molecular Similarity Indices Analysis (CoMSIA) analysis for Model A a .

\begin{tabular}{|c|c|c|c|c|c|c|c|c|c|c|c|}
\hline \multirow{2}{*}{ Models } & \multirow{2}{*}{$q^{2}$} & \multirow{2}{*}{$\mathbf{N}$} & \multirow{2}{*}{ SEP } & \multirow{2}{*}{ SEE } & \multirow{2}{*}{$\mathbf{r}_{\mathrm{ncv}}{ }^{2}$} & \multirow{2}{*}{$\mathbf{F}$} & \multicolumn{5}{|c|}{ Relative \% Contributions } \\
\hline & & & & & & & $S$ & $\mathrm{E}$ & $\mathrm{H}$ & D & A \\
\hline CoMFA-S & -0.396 & 1 & 0.336 & 0.183 & 0.584 & 26.690 & 1 & - & - & - & - \\
\hline CoMFA-E & 0.622 & 2 & 0.180 & 0.109 & 0.860 & 55.213 & - & 1 & - & - & - \\
\hline CoMFA-SE & 0.607 & 2 & 0.183 & 0.09 & 0.904 & 84.813 & 35.6 & 64.4 & - & - & - \\
\hline COMSIA-S & -0.164 & 10 & 0.479 & 0.057 & 0.982 & 59.415 & 1 & - & - & - & - \\
\hline COMSIA-E & 0.570 & 12 & 0.305 & 0.009 & 1.000 & 1876.640 & - & 1 & - & - & - \\
\hline CoMSIA-H & 0.286 & 3 & 0.278 & 0.098 & 0.912 & 61.914 & - & - & 1 & - & - \\
\hline CoMSIA-D & 0.326 & 3 & 0.270 & 0.150 & 0.792 & 22.83 & - & - & - & 1 & - \\
\hline COMSIA-A & 0.649 & 4 & 0.200 & 0.063 & 0.965 & 117.696 & - & - & - & - & 1 \\
\hline CoMSIA-SE & 0.596 & 12 & 0.296 & 0.004 & 1.000 & $12,519.923$ & 23.0 & 77.0 & - & - & - \\
\hline CoMSIA-SEH & 0.573 & 13 & 0.323 & 0.002 & 1.000 & $55,261.759$ & 11.7 & 59.4 & 29.0 & - & - \\
\hline CoMSIA-SEHD & 0.581 & 6 & 0.233 & 0.010 & 0.999 & 3325.404 & 7.5 & 35.3 & 19.1 & 38.1 & - \\
\hline CoMSIA-SEHA & 0.639 & 8 & 0.233 & 0.011 & 0.999 & 1953.948 & 7.1 & 37.8 & 17.3 & - & 37.9 \\
\hline CoMSIA-SED & 0.589 & 6 & 0.231 & 0.013 & 0.999 & 1782.188 & 11.0 & 45.0 & - & 44.0 & - \\
\hline CoMSIA-SEA & 0.697 & 10 & 0.232 & 0.006 & 1.000 & 5084.953 & 10.2 & 44.6 & - & - & 45.2 \\
\hline CoMSIA-SEDA & 0.662 & 7 & 0.217 & 0.010 & 0.999 & 2619.974 & 6.3 & 33.3 & & 31.9 & 28.5 \\
\hline CoMSIA-SH & 0.253 & 3 & 0.284 & 0.095 & 0.917 & 66.043 & 23.1 & - & 76.9 & - & - \\
\hline CoMSIA-SD & 0.255 & 2 & 0.276 & 0.156 & 0.761 & 30.321 & 14.9 & - & - & 85.1 & - \\
\hline CoMSIA-SA & 0.576 & 4 & 0.220 & 0.058 & 0.971 & 142.753 & 16.4 & - & - & - & 83.6 \\
\hline CoMSIA-SHD & 0.462 & 11 & 0.324 & 0.001 & 1.000 & $89,668.574$ & 10.9 & - & 39.3 & 49.8 & - \\
\hline CoMSIA-SHA & 0.536 & 4 & 0.231 & 0.049 & 0.979 & 202.281 & 10.2 & - & 32.1 & - & 57.7 \\
\hline CoMSIA-SDA & 0.490 & 4 & 0.242 & 0.071 & 0.956 & 92.436 & 9.5 & - & - & 40.1 & 50.4 \\
\hline CoMSIA-SHDA & 0.514 & 12 & 0.324 & 0.001 & 1.000 & $87,368.769$ & 6.6 & - & 26.5 & 35.7 & 31.2 \\
\hline CoMSIA-EH & 0.602 & 13 & 0.311 & 0.002 & 1.000 & $60,678.767$ & - & 63.8 & 36.2 & - & - \\
\hline CoMSIA-ED & 0.601 & 6 & 0.228 & 0.019 & 0.997 & 876.360 & - & 49.8 & - & 50.2 & - \\
\hline CoMSIA-EA & 0.723 & 7 & 0.239 & 0.004 & 1.000 & $11,379.460$ & - & 49.1 & - & - & 50.9 \\
\hline CoMSIA-EHD & 0.598 & 6 & 0.229 & 0.011 & 0.999 & 2455.905 & - & 37.3 & 21.7 & 41.0 & - \\
\hline CoMSIA-EHA & 0.660 & 5 & 0.204 & 0.022 & 0.996 & 794.462 & - & 37.6 & 21.2 & - & 41.2 \\
\hline CoMSIA-EDA & 0.682 & 7 & 0.210 & 0.011 & 0.999 & 2511.362 & - & 34.6 & - & 34.5 & 30.9 \\
\hline CoMSIA-EHDA & 0.647 & 6 & 0.214 & 0.013 & 0.999 & 2074.207 & - & 28.5 & 15.1 & 30.7 & 25.7 \\
\hline CoMSIA-HD & 0.516 & 11 & 0.307 & 0.001 & 1.000 & $92,707.250$ & - & - & 45.5 & 54.5 & - \\
\hline CoMSIA-HA & 0.571 & 4 & 0.222 & 0.049 & 0.979 & 196.681 & - & - & 36.9 & - & 63.1 \\
\hline CoMSIA-HDA & 0.555 & 9 & 0.269 & 0.007 & 1.000 & 4120.755 & - & - & 28.5 & 37.9 & 33.6 \\
\hline CoMSIA-DA & 0.559 & 12 & 0.309 & 0.042 & 0.992 & 93.531 & - & - & - & 46.0 & 54.0 \\
\hline CoMSIA-ALL & 0.631 & 6 & 0.219 & 0.013 & 0.999 & 2002.943 & 5.0 & 27.7 & 13.9 & 29.1 & 24.3 \\
\hline
\end{tabular}

${ }^{a} \mathrm{~N}$ is the optimal number of components, $\mathrm{q}^{2}$ is the square of the LOO cross-validation (CV) coefficient, SEP is the standard error of prediction, $\mathrm{rncv}^{2}$ is the square of the non-CV coefficient, SEE is the standard error of estimation of non-CV analysis, $\mathrm{F}$ is the F-test value. S, E, H, D, and A are the steric, electrostatic, hydrophobic, hydrogen-bond donor and hydrogen-bond acceptor fields contribution, the best selected CoMFA and CoMSIA models are highlighted in bold character. 
Table 2. Summary of results from CoMFA and CoMSIA analysis for Model B ${ }^{\mathrm{a}}$.

\begin{tabular}{|c|c|c|c|c|c|c|c|c|c|c|c|}
\hline \multirow{2}{*}{ Models } & \multirow{2}{*}{$q^{2}$} & \multirow{2}{*}{$\mathbf{N}$} & \multirow{2}{*}{ SEP } & \multirow{2}{*}{ SEE } & \multirow{2}{*}{$\mathrm{r}_{\mathrm{ncv}}{ }^{2}$} & \multirow{2}{*}{$\mathbf{F}$} & \multicolumn{5}{|c|}{ Relative \% Contributions } \\
\hline & & & & & & & $S$ & E & $\mathbf{H}$ & D & A \\
\hline CoMFA-S & -0.114 & 2 & 0.239 & 0.116 & 0.739 & 32.512 & 1 & - & - & - & - \\
\hline CoMFA-E & 0.803 & 2 & 0.100 & 0.060 & 0.930 & 152.542 & - & 1 & - & - & - \\
\hline COMFA-SE & 0.810 & 3 & 0.101 & 0.041 & 0.968 & 221.25 & 28.2 & 71.8 & - & - & - \\
\hline CoMSIA-S & 0.285 & 1 & 0.276 & 0.225 & 0.145 & 4.082 & 1 & - & - & - & - \\
\hline CoMSIA-E & 0.585 & 3 & 0.164 & 0.091 & 0.872 & 49.948 & - & 1 & - & - & - \\
\hline CoMSIA-H & 0.367 & 3 & 0.203 & 0.104 & 0.833 & 36.509 & - & - & 1 & - & - \\
\hline CoMSIA-D & 0.200 & 2 & 0.223 & 0.161 & 0.584 & 16.162 & - & . & - & 1 & - \\
\hline CoMSIA-A & 0.339 & 3 & 0.207 & 0.123 & 0.767 & 24.199 & - & 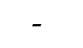 & - & - & 1 \\
\hline CoMSIA-SE & 0.618 & 3 & 0.158 & 0.076 & 0.91 & 74.262 & 22.6 & 77.4 & - & - & - \\
\hline CoMSIA-SEH & 0.604 & 3 & 0.160 & 0.067 & 0.932 & 100.153 & 13.8 & 57.7 & 28.5 & - & - \\
\hline CoMSIA-SEHD & 0.710 & 8 & 0.156 & 0.017 & 0.996 & 601.957 & 9.3 & 34.0 & 21.7 & 35.0 & - \\
\hline CoMSIA-SEHA & 0.711 & 10 & 0.166 & 0.012 & 0.998 & 985.125 & 9.6 & 35.3 & 22.6 & - & 32.5 \\
\hline CoMSIA-SED & 0.628 & 3 & 0.155 & 0.068 & 0.929 & 96.290 & 14.8 & 45.6 & - & 39.6 & - \\
\hline CoMSIA-SEA & 0.657 & 3 & 0.149 & 0.069 & 0.927 & 92.442 & 14.7 & 45.8 & - & - & 39.5 \\
\hline CoMSIA-SEDA & 0.609 & 3 & 0.159 & 0.074 & 0.915 & 79.125 & 11.1 & 34.1 & - & 31.0 & 23.8 \\
\hline CoMSIA-SH & 0.269 & 3 & 0.218 & 0.107 & 0.824 & 34.261 & 23.5 & - & 76.5 & - & - \\
\hline CoMSIA-SD & 0.413 & 9 & 0.229 & 0.026 & 0.992 & 231.079 & 32.7 & - & - & 67.3 & - \\
\hline CoMSIA-SA & 0.548 & 20 & 0.359 & 0.003 & 1.000 & 7159.795 & 25.0 & - & - & - & 75.0 \\
\hline CoMSIA-SHD & 0.633 & 5 & 0.162 & 0.047 & 0.970 & 127.937 & 15.2 & - & 36.2 & 48.7 & - \\
\hline CoMSIA-SHA & 0.69 & 19 & 0.272 & 0.001 & 1.000 & $86,018.515$ & 15.5 & - & 33.9 & - & 50.7 \\
\hline CoMSIA-SDA & 0.458 & 5 & 0.197 & 0.051 & 0.964 & 107.301 & 19.1 & - & - & 42.6 & 38.3 \\
\hline CoMSIA-SHDA & 0.639 & 5 & 0.161 & 0.044 & 0.973 & 146.386 & 11.4 & - & 25.7 & 35.7 & 27.3 \\
\hline CoMSIA-EH & 0.624 & 14 & 0.221 & 0.004 & 1.000 & 5870.861 & - & 61.1 & 38.9 & - & - \\
\hline COMSIA-ED & 0.579 & 3 & 0.165 & 0.086 & 0.886 & 56.746 & - & 53.5 & - & 46.5 & - \\
\hline CoMSIA-EA & 0.599 & 3 & 0.161 & 0.086 & 0.886 & 56.816 & - & 54.1 & - & - & 45.9 \\
\hline CoMSIA-EHD & 0.705 & 8 & 0.157 & 0.019 & 0.996 & 513.854 & - & 37.4 & 26.9 & 35.7 & - \\
\hline CoMSIA-EHA & 0.719 & 8 & 0.154 & 0.019 & 0.996 & 492.026 & - & 39.2 & 27.4 & - & 33.4 \\
\hline CoMSIA-EDA & 0.562 & 3 & 0.169 & 0.090 & 0.876 & 51.739 & - & 38.3 & - & 35.3 & 26.5 \\
\hline CoMSIA-EHDA & 0.686 & 8 & 0.162 & 0.019 & 0.996 & 512.390 & - & 29.7 & 22.9 & 27.9 & 19.5 \\
\hline CoMSIA-HD & 0.625 & 5 & 0.164 & 0.051 & 0.963 & 104.326 & - & - & 47.4 & 52.6 & - \\
\hline CoMSIA-HA & 0.666 & 19 & 0.282 & 0.001 & 1.000 & $14,7123.304$ & - & - & 44.3 & - & 55.7 \\
\hline CoMSIA-HDA & 0.621 & 5 & 0.165 & 0.049 & 0.966 & 114.981 & - & - & 32.4 & 38.9 & 28.8 \\
\hline CoMSIA-DA & 0.245 & 2 & 0.217 & 0.143 & 0.669 & 23.220 & - & - & - & 57.0 & 43.0 \\
\hline CoMSIA-ALL & 0.7 & 9 & 0.164 & 0.014 & 0.998 & 755.591 & 8.1 & 27.4 & 18.1 & 27.0 & 19.5 \\
\hline
\end{tabular}

${ }^{\text {a }} \mathrm{N}$ is the optimal number of components, $\mathrm{q}^{2}$ is the square of the LOO cross-validation (CV) coefficient, SEP is the standard error of prediction, $\mathrm{rncv}^{2}$ is the square of the non-CV coefficient, SEE is the standard error of estimation of non-CV analysis, F is the F-test value. S, E, H, D and A are the steric, electrostatic, hydrophobic, hydrogen-bond donor and hydrogen-bond acceptor fields contribution, the best selected CoMFA and CoMSIA models are highlighted in bold character.

\section{CoMFA}

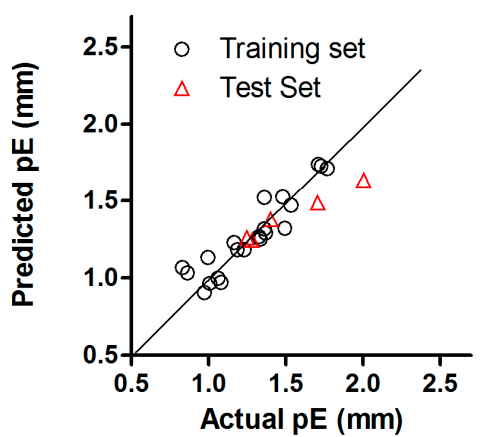

CoMSIA

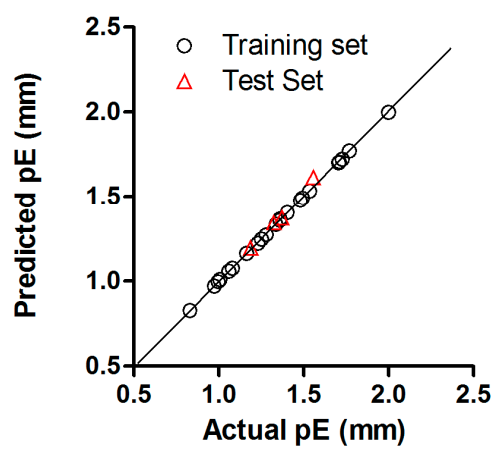

Figure 2. Scatter plots of actual versus predicted $\mathrm{pE}$ values by CoMFA (left) and CoMSIA (right) analysis for Model A. 
CoMFA

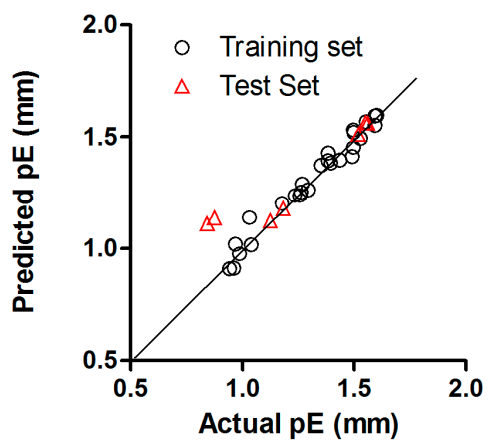

COMSIA

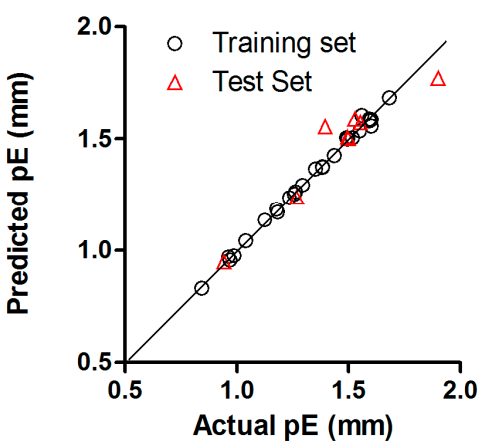

Figure 3. Scatter plots of actual versus predicted $\mathrm{pE}$ values by CoMFA (left) and CoMSIA (right) analysis for Model B.

Table 3. Actual and predicted $\mathrm{pE}$ values of molecules in the Model A generated through the best CoMFA and CoMSIA analysis ${ }^{\mathrm{a}}$.

\begin{tabular}{|c|c|c|c|c|c|}
\hline \multirow{2}{*}{ Molecule } & \multirow{2}{*}{ Actual pE (mm) } & \multicolumn{2}{|c|}{ CoMFA } & \multicolumn{2}{|c|}{ CoMSIA } \\
\hline & & Predicted pE (mm) & Residual & Predicted pE (mm) & Residual \\
\hline $1 \mathbf{a}$ & 1.5318 & 1.4708 & 0.06 & 1.5338 & 0.00 \\
\hline $2 a$ & 1.0056 & 0.9666 & 0.04 & 1.0086 & 0.00 \\
\hline $3 a$ & 1.4790 & 1.5260 & -0.05 & 1.4780 & 0.00 \\
\hline $4 a$ & 1.3336 & 1.2516 & 0.08 & 1.3326 & 0.00 \\
\hline $5 a$ & 1.0580 & 0.9970 & 0.06 & 1.0570 & 0.00 \\
\hline $6 a^{t}$ & 2.0000 & 1.6380 & 0.36 & 1.9990 & 0.00 \\
\hline $7 a^{t, u}$ & 1.5544 & 1.4410 & 0.11 & 1.6120 & -0.06 \\
\hline $8 a^{u}$ & 0.8617 & 1.0327 & -0.17 & 1.1680 & -0.31 \\
\hline $9 a$ & 1.7667 & 1.7127 & 0.05 & 1.7687 & 0.00 \\
\hline $10 a^{u}$ & 1.3688 & 1.2908 & 0.08 & 1.3730 & 0.00 \\
\hline $11 a$ & 1.7263 & 1.7293 & 0.00 & 1.7243 & 0.00 \\
\hline $12 \mathbf{a}^{\mathrm{u}}$ & 0.8125 & 1.4180 & -0.61 & 1.3220 & -0.51 \\
\hline $13 a$ & 1.4901 & 1.3231 & 0.17 & 1.4941 & 0.00 \\
\hline $14 a^{t}$ & 1.2470 & 1.2600 & -0.01 & 1.2474 & 0.00 \\
\hline $15 a$ & 0.9943 & 1.1333 & -0.14 & 0.9953 & 0.00 \\
\hline $16 a$ & 1.3590 & 1.5220 & -0.16 & 1.3670 & -0.01 \\
\hline $17 a$ & 1.2275 & 1.1835 & 0.04 & 1.2245 & 0.00 \\
\hline $18 a^{t}$ & 1.7046 & 1.4880 & 0.22 & 1.6996 & 0.01 \\
\hline $19 a^{u}$ & 1.3230 & 1.2650 & 0.06 & 1.3420 & -0.02 \\
\hline $20 a$ & 1.3590 & 1.3170 & 0.04 & 1.3588 & 0.00 \\
\hline $21 a$ & 1.7068 & 1.7398 & -0.03 & 1.7058 & 0.00 \\
\hline $22 a^{u}$ & 1.1854 & 1.1804 & 0.01 & 1.1940 & -0.01 \\
\hline $23 a^{t}$ & 1.4013 & 1.3800 & 0.02 & 1.4033 & 0.00 \\
\hline $24 a$ & 1.0773 & 0.9713 & 0.11 & 1.0753 & 0.00 \\
\hline $25 a$ & 0.8295 & 1.0695 & -0.24 & 0.8265 & 0.00 \\
\hline $26 a$ & 0.9708 & 0.9068 & 0.06 & 0.9706 & 0.00 \\
\hline $27 a^{t}$ & 1.2779 & 1.2430 & 0.03 & 1.2749 & 0.00 \\
\hline
\end{tabular}

${ }^{\text {a }}$ CoMFA-E, and CoMSIA-EA, $10^{-9} \mathrm{M}$ assay. ${ }^{\mathrm{t}}$ test set compounds used in CoMFA, ${ }^{\mathrm{u}}$ test set compounds used in CoMSIA. 
Table 4. Actual and predicted $\mathrm{pE}$ values of molecules in the Model B generated through the best CoMFA and CoMSIA analysis ${ }^{a}$.

\begin{tabular}{|c|c|c|c|c|c|}
\hline \multirow{2}{*}{ Molecule } & \multirow{2}{*}{ Actual pE (mm) } & \multicolumn{2}{|c|}{ CoMFA } & \multicolumn{2}{|c|}{ CoMSIA } \\
\hline & & Predicted pE $(\mathrm{mm})$ & Residual & Predicted $\mathrm{pE}(\mathrm{mm})$ & Residual \\
\hline $1 b$ & 1.4942 & 1.4542 & 0.04 & 1.4992 & -0.01 \\
\hline $2 b^{u}$ & 1.2655 & 1.2905 & -0.03 & 1.2400 & 0.03 \\
\hline $3 b^{t}$ & 1.1245 & 1.1260 & 0.00 & 1.1385 & -0.01 \\
\hline $4 b$ & 1.2946 & 1.2646 & 0.03 & 1.2956 & 0.00 \\
\hline $5 b$ & 1.0394 & 1.0184 & 0.02 & 1.0454 & -0.01 \\
\hline $6 b$ & 0.9688 & 1.0188 & -0.05 & 0.9578 & 0.01 \\
\hline $7 \mathrm{~b}$ & 1.0321 & 1.1411 & -0.11 & 1.4260 & -0.39 \\
\hline $8 b^{t}$ & 0.8410 & 1.1134 & -0.27 & 0.8320 & 0.01 \\
\hline $9 b$ & 0.1643 & 1.0641 & -0.90 & 1.1240 & -0.96 \\
\hline $10 \mathrm{~b}$ & 1.4344 & 1.3964 & 0.04 & 1.4284 & 0.01 \\
\hline $11 b$ & 1.2343 & 1.2393 & -0.01 & 1.2373 & 0.00 \\
\hline $12 b$ & 1.2569 & 1.2409 & 0.02 & 1.2539 & 0.00 \\
\hline $13 b$ & 1.3818 & 1.4298 & -0.05 & 1.3778 & 0.00 \\
\hline $14 \mathrm{~b}$ & 1.3818 & 1.3958 & -0.01 & 1.3738 & 0.01 \\
\hline $15 b^{u}$ & 1.4942 & 1.5332 & -0.04 & 1.5100 & -0.02 \\
\hline $16 b$ & 1.4891 & 1.4141 & 0.08 & 1.5071 & -0.02 \\
\hline $17 b^{t}$ & 1.5579 & 1.5627 & 0.00 & 1.6059 & -0.05 \\
\hline $18 b^{u}$ & 1.5260 & 1.4940 & 0.03 & 1.5890 & -0.06 \\
\hline $19 b$ & 1.5916 & 1.5956 & 0.00 & 1.5826 & 0.01 \\
\hline $20 b^{u}$ & 1.8987 & 1.5444 & 0.35 & 1.7690 & 0.13 \\
\hline $21 b^{u}$ & 1.5513 & 1.5693 & -0.02 & 1.5760 & -0.02 \\
\hline $22 b$ & 1.5997 & 1.5977 & 0.00 & 1.5577 & 0.04 \\
\hline $23 b$ & 1.3511 & 1.3751 & -0.02 & 1.3671 & -0.02 \\
\hline $24 b$ & 1.5916 & 1.5526 & 0.04 & 1.5896 & 0.00 \\
\hline $25 b^{u}$ & 1.3948 & 1.3858 & 0.01 & 1.5560 & -0.16 \\
\hline $26 b$ & 1.5997 & 1.3252 & 0.27 & 1.5887 & 0.01 \\
\hline $6 a$ & 2.0000 & 1.4404 & 0.56 & 1.5060 & 0.49 \\
\hline $8 a^{t}$ & 1.5490 & 1.5644 & -0.02 & 1.5380 & 0.01 \\
\hline $10 a^{u}$ & 1.4967 & 1.5217 & -0.03 & 1.5030 & -0.01 \\
\hline $12 a^{t}$ & 1.5165 & 1.5136 & 0.00 & 1.5045 & 0.01 \\
\hline $15 a$ & 1.2612 & 1.2562 & 0.01 & 1.2652 & 0.00 \\
\hline $21 a$ & 1.6812 & 1.3303 & 0.35 & 1.6852 & 0.00 \\
\hline $22 a$ & 1.1750 & 1.2050 & -0.03 & 1.1850 & -0.01 \\
\hline $23 a^{u}$ & 0.9425 & 0.9105 & 0.03 & 0.9510 & -0.01 \\
\hline $24 a^{t}$ & 1.1803 & 1.1804 & 0.00 & 1.1733 & 0.01 \\
\hline $25 a^{t}$ & 0.8740 & 1.1388 & -0.26 & 1.1280 & -0.25 \\
\hline $26 a$ & 0.9602 & 0.9132 & 0.05 & 0.9732 & -0.01 \\
\hline $27 a$ & 0.9855 & 0.9785 & 0.01 & 0.9785 & 0.01 \\
\hline
\end{tabular}

${ }^{\text {a }}$ CoMFA-SE, and CoMSIA-EHA, $10^{-10} \mathrm{M}$ assay. ${ }^{\mathrm{t}}$ test set compounds used in CoMFA, ${ }^{\mathrm{u}}$ test set compounds used in COMSIA.

\subsubsection{CoMFA Statistics}

The analysis of the obtained 3D-QSAR models (Tables 1 and 2) showed that the best CoMFA models are not always obtained using a combination of electrostatic and steric fields. Model A, using electrostatic field, produced a cross-validated $\mathrm{q}^{2}$ of 0.622 with an optimum number of components $N=2$ and a non-cross-validated $\mathrm{r}_{\mathrm{ncv}}{ }^{2}$ value of 0.860 . Model B, using both steric and electrostatic fields, gave a cross validated $\mathrm{q}^{2}$ value of 0.810 with an optimum number of components $N=3$, a non-cross-validated $\mathrm{r}_{\mathrm{ncv}}{ }^{2}$ of 0.968 , an estimated F-value of 221.25, and low standard error of estimation (SEE) value of 0.041, while the contribution of steric and electrostatic fields was $28.2 \%$ and $71.8 \%$, respectively. 


\subsubsection{CoMSIA Statistics}

Unlike CoMFA, CoMSIA has the advantage that it generates more information. The fields obtained by CoMSIA are steric (S), electrostatic (E), hydrophobic $(\mathrm{H})$, hydrogen-bond donor (D), and hydrogen-bond acceptor (A) fields. Thirty-one different CoMSIA models were developed using various combinations of CoMSIA descriptor fields (Tables 1 and 2). The satisfactory $q^{2}, r_{n c v}{ }^{2}$, and $r^{2}$ pred values of the models were the most important selection criterion for the selection of the best CoMSIA model. In Model A, the best field contribution was CoMSIA-EA, which has a good cross-validated correlation coefficient $\mathrm{q}^{2}$ value of 0.723 with an optimum number of components $N=7$, a significant $\mathrm{r}_{\text {ncv }}{ }^{2}$ of 1.000, lower SEE of 0.004 , and higher F-value of 11,379.460. The electrostatic and hydrogen-bond acceptor descriptors had $49.1 \%$ and $50.9 \%$ of relative contributions. On the other hand, in Model B, the best combination of descriptors was CoMSIA-EHA, that was built using eight components and has cross-validated $\mathrm{q}^{2}$ value of 0.719 , while the non-cross-validated $\mathrm{r}_{\text {ncv }}{ }^{2}$ was 0.996 , with a low SEE of 0.019 and an estimated high F-value of 492.026. Electrostatic, hydrophobic, and hydrogen-bond acceptor contributions were found to be $39.2 \%, 55.7 \%, 27.4$, and $33.4 \%$, respectively.

\subsection{Validation of the $3 D-Q S A R$ Models}

The best CoMFA and CoMSIA models were generated employing PLS analysis, which produced the cross-validated coefficients $\mathrm{q}^{2}$. A 3D-QSAR model should possess a high $\mathrm{q}^{2}$ value, but this is not the only condition that a model must exhibit in order to have an adequate predictive capacity [22]. For this purpose, we carried out the external validation of the 3D-QSAR models. The external validation was carried out by setting aside a test set of compounds not included in the construction of the model. The $\mathrm{r}^{2}$ pred values of the CoMFA models, A and B, were found to be 0.751 and 0.770 , while the $r_{m}^{2}$ had a value of 0.561 and 0.640 for models $A$ and $B$, respectively. On the other hand, our results indicate that CoMSIA models were able to describe the test set variance with a high predictability for both models. This is demonstrated by the high $\mathrm{r}^{2}$ pred values obtained for all models (Model A, $\mathrm{r}^{2}$ pred $=0.946$, $r_{m}^{2}=0.875$; Model B, $\mathrm{r}_{\text {pred }}^{2}=0.923, r_{m}^{2}=0.880$ ).

The CoMFA model B together with the CoMSIA models A and B passed Tropsha's recommended test for predictive ability, unlike the CoMFA model A, whose $r_{0}^{\prime 2}$ did not come close to value of $r^{2}$ and $\left(r^{2}-r_{0}^{\prime 2}\right) / r^{2}$ value was $>0.1$. The statistical parameters of the predictability of the best CoMFA and CoMSIA analysis, and the acceptability criteria of the QSAR models are represented in the Tables 5 and 6.

Table 5. Statistical parameters of the predictability of the best CoMFA and CoMSIA analysis ${ }^{\text {a }}$.

\begin{tabular}{cccc}
\hline & SD & PRESS & $\mathbf{r}_{\text {pred }}$ \\
\hline $\mathbf{1 0}^{-\mathbf{9}} \mathbf{M}$ & & & \\
CoMFA-E & 0.7219 & 0.1798 & 0.751 \\
CoMSIA-EA & 0.0699 & 0.0038 & 0.946 \\
$\mathbf{1 0}^{-10} \mathbf{M}$ & & & \\
CoMFA-SE & 0.6282 & 0.1446 & 0.770 \\
CoMSIA-EHA & 0.6269 & 0.0484 & 0.923 \\
\hline
\end{tabular}

a $\mathrm{SD}$ is the sum of the squared deviations between the biological activity of molecules in the test set and mean activity of the training set molecules, PRESS is the sum of the squared deviations between predicted and actual biological activity values for every molecule in the test set, $\mathrm{r}^{2}$ pred is the predictive correlation coefficient based only on the test set molecules. 
Table 6. External validation characteristics of different models according to Golbraikh and Tropsha [22].

\begin{tabular}{lccccc}
\hline \multirow{2}{*}{ Parameters } & \multirow{2}{*}{ Threshold Value } & \multicolumn{3}{c}{ Test Results } \\
\cline { 3 - 5 } & & \multicolumn{2}{c}{ Model A } & \multicolumn{2}{c}{ Model B } \\
\cline { 3 - 5 } & & CoMFA & CoMSIA & CoMFA & CoMSIA \\
\hline $\mathrm{q}^{2}$ & $>0.5$ & 0.622 & 0.723 & 0.810 & 0.719 \\
$\mathrm{r}^{2}$ & $>0.6$ & 974 & 0.994 & 0.884 & 0.911 \\
$\mathrm{r}^{\prime 2}$ & Close to value of $r^{2}$ & 0.794 & 0.980 & 0.808 & 0.909 \\
$\mathrm{k}^{\prime}$ & $0.85<k^{\prime}<1.15$ & 1.098 & 0.983 & 0.949 & 0.990 \\
$\left(\mathrm{r}^{2}-\mathrm{r}_{0}^{\prime 2}\right) / \mathrm{r}^{2}$ & $<0.1$ & 0.185 & 0.014 & 0.086 & 0.001 \\
$\mathrm{r}_{\mathrm{m}}^{2}$ & $>0.5$ & 0.561 & 0.875 & 0.640 & 0.880 \\
\hline
\end{tabular}

\subsection{D-QSAR Contour Maps}

Unlike a 2D-QSAR equation, the results of a 3D-QSAR study can be viewed graphically. The color contour maps obtained show the regions of the molecule where structural modifications can be made. With this information, it is possible to propose changes in the steric, electrostatic, hydrophobic, and hydrogen bonding properties of the studied compounds. With the structure-activity relationship thus obtained, it is possible to rationally design new brassinosteroids with promising biological activity. The contour maps obtained from CoMFA and CoMSIA models, along with template compound, are shown in Figures 4 and 5. Compound 6a, the most active of the series, has been selected as the reference structure in each presented map.

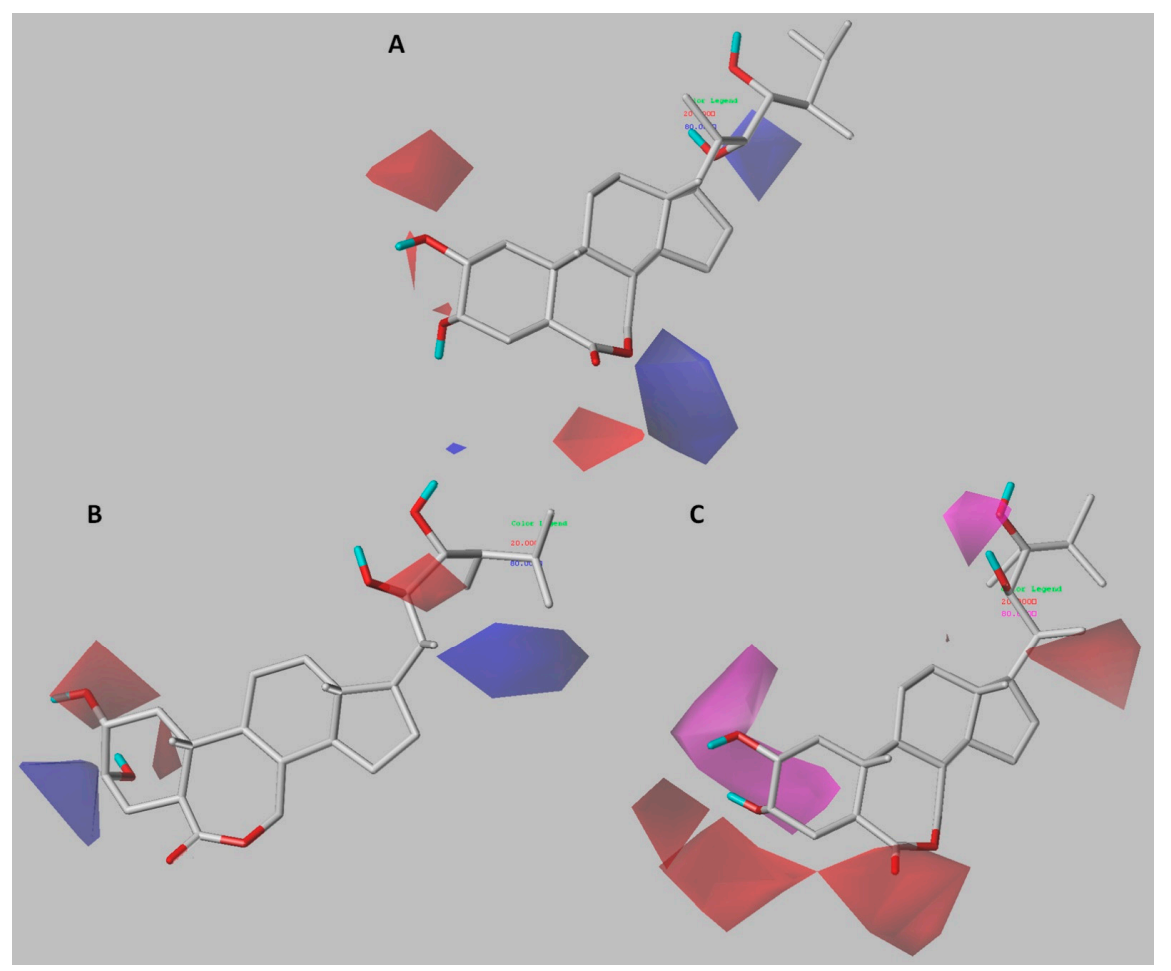

Figure 4. CoMFA and CoMSIA contour maps of Model A around the most active compound 6a. CoMFA contour maps: (A) electrostatic field distribution, electronegative (red) and electropositive (blue) favorable fields; CoMSIA contour maps: (B) electrostatic field contribution, the colors have the same meaning as in CoMFA contour maps, and (C) hydrogen-bond acceptor field contribution, favorable (magenta) and unfavorable (red). 


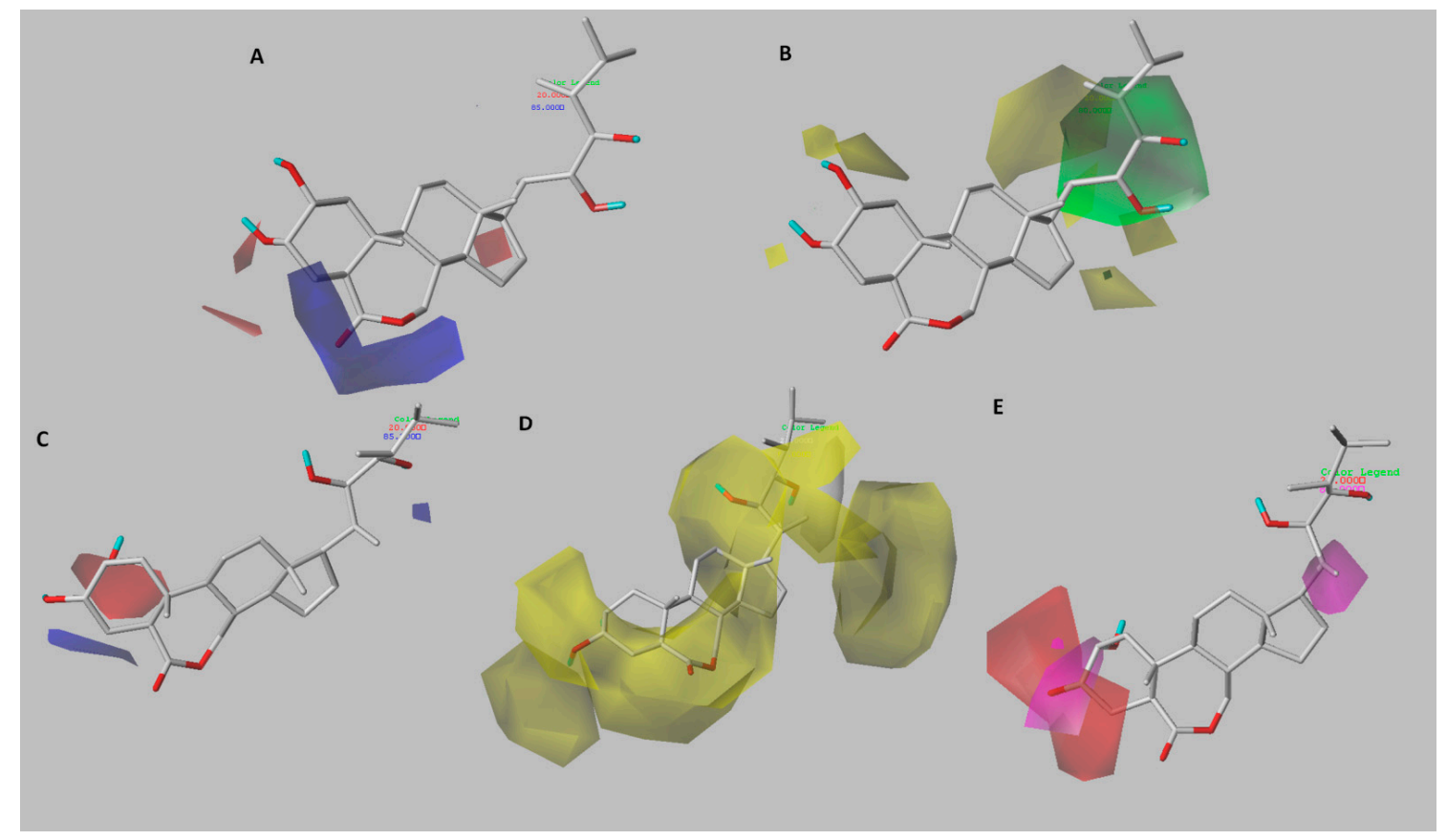

Figure 5. CoMFA and CoMSIA contour maps for brassinosteroids ligands of the Model B. Compound 6a (most active of the series) is shown inside the fields. CoMFA contour maps: (A) electrostatic field contribution, electropositive (blue) and electronegative (red) favorable fields, and (B) steric field contribution, favorable (green) and unfavorable (yellow); CoMSIA contour maps: (C) electrostatic field distribution, the colors have the same meaning as in CoMFA contour maps, (D) hydrophobic field distribution, favorable (yellow) and unfavorable (white), and (E) hydrogen-bond acceptor field contribution, favorable (magenta) and unfavorable (red).

\section{Discussion}

\subsection{Analysis of CoMFA Contour Maps}

\subsubsection{Model A}

Figure $4 \mathrm{a}$ depicts the distribution of electrostatic field using compound $\mathbf{6 a}$ as a reference structure. The blue and red ( $80 \%$ and $20 \%$ contributions) contour maps represent favorable electropositive charge areas and favorable electronegative charge areas, respectively. A big blue polyhedron is present near the 7th position of the brassinolide 6 a (on the top part of the lactone ring), which suggests that electron-donating groups at this position would be favorable. This can be proven experimentally by considering the low activity of the compounds $\mathbf{2} \mathbf{a}, \mathbf{4} \mathbf{a}, \mathbf{5} \mathbf{a}$, and $\mathbf{8} \mathbf{a}$, which direct the 7 -oxo group at the B-ring toward the blue contour, unlike compounds with the carbonyl group oriented under the plane that show a higher activity (6a, 18a and 21a). Therefore, a pattern of type 7-oxolactone in B-ring would be less favorable, which is consistent with previous reports indicating that type 6-oxolactone brassinosteroid analogs are more active [15]. Moreover, the spatial orientation of the carbonyl group is influenced by the position of the hydroxyl substituents on the A-ring. The compounds $7 \mathbf{a}$ and $9 \mathbf{a}$ have a 2,3-dihydroxy substitution pattern, and they project the carbonyl group under the plane that is favorable for the activity, while the homologues 8a and 10a have a 3,4-dihydroxy substitution pattern that disfavors the B-ring conformation, causing the carbonyl group to be projected toward blue contour. Two red regions are sighted in the proximity of the $\alpha$-oriented hydroxyl groups at C-2 and C-3 positions. This suggests that electronegative substitutions are favorable for growth-promoting activity (e.g., compounds 3a, 7a, 13a, 11a, and 21a), whereas compounds with the $\beta$-oriented hydroxyl groups at C-2 and C-3 positions showed lower activity (e.g., compounds 22a, 23a, 24a, 26a, and 27a). 
The $\alpha$-oriented hydroxyl group at A-ring has been reported to be essential for greater biological activity [5].

\subsubsection{Model B}

Figure $5 \mathrm{a}, \mathrm{b}$ show the distribution of steric and electrostatic fields around compound $\mathbf{6 a}$. In the steric contour map ( $80 \%$ and $20 \%$ contributions), green polyhedrons show regions where the increase in volume improves activity. While yellow polyhedrons indicate that the increase in volume is unfavorable for activity. Two yellow regions are found around the hydroxyl group at C-2 position, suggesting that the presence of bulky groups at this position disfavor the activity. The presence of these yellow isopleths supports previous reports regarding the presence of the hydroxyl group at $2-\alpha$ position as not indispensable to elicit the biological activity [23]. This can be explained by the fact that compounds such as $\mathbf{2 b}, \mathbf{3 b}, \mathbf{1 2 b}, \mathbf{1 0 b}, \mathbf{7 b}, \mathbf{1 8 b}, \mathbf{1 3 b}$, and $\mathbf{2 0 b}$ exhibited comparable activity values, with respect to those that did have $2-\alpha$ substitution (e.g., compounds $4 \mathbf{b}, \mathbf{5 b}, \mathbf{2 1 b}, \mathbf{2 3 b}, \mathbf{6 a}, \mathbf{2 1 a}$ ). Furthermore, the presence of a large green contour around the side chain, that is flanked by yellow isopleths, would allow a limited increase in volume in this region, in order to improve the biological activity of BRs. In fact, a group of compounds referred to as "superbrassinolides" has been described, that had superior activity to brassinolide. This series of derivatives contained chains of varying length and cycloalkyl groups with different ring sizes at C-24, reaching the conclusion that the bioactivity clearly increased inversely with the chain length [14]. Therefore, excessive chain elongation prevents adequate binding to the receptor.

The map of electrostatic contours ( $85 \%$ and $20 \%$ contributions) shows red and blue polyhedrons. Red polyhedrons show areas where the presence of electronegative atoms improves biological activity. While blue polyhedrons show areas where electro-positive atoms are favorable for biological activity. One big blue contour surrounding the positions C-4 to C-8 of the A and B-rings indicates that the electropositive potential favors the activity. Therefore, the presence of a polar functional group from the B-ring is not essential for biological activity (e.g., 12a), which appears to be in strong contrast with the structure requirements mentioned in previous papers [24]. This information is consistent with the electrostatic field contour map for CoMFA-model A.

\subsection{Analysis of CoMSIA Contour Maps}

\subsubsection{Model A}

The contour plots for CoMSIA-EA are presented in Figure $4 b, c$, which illustrates the electrostatic and hydrogen-bond acceptor fields using compound $\mathbf{6 a}$ as reference structure. All contour maps were generated with $80 \%$ and $20 \%$ contributions for favorable and unfavorable interactions, respectively.

The electrostatic field effect is shown in Figure $4 b$, two red isopleths are sighted in the $\alpha$-hydroxyls at C-2 and C-3 positions, suggesting that electron-withdrawing groups are favorable to increase activity, as it was also observed in the electrostatic contour map for CoMFA-model A. One blue contour around the $\beta$-position at $C-3$ shows that the presence of electronegative groups in the $\alpha$-position generates charge deficiency on either the carbon or hydrogen atom in the same position, which is favorable for biological activity. A red contour around the hydroxyl group at C-22 position of the brassinolide side chain suggests that this group is more important for the activity than the hydroxyl group at C-23 position. This is in accordance with previous reports, which consider that having a 22,23-vicinal diol in the side chain of a compound is not absolutely necessary to exhibit typical brassinosteroid activity [25], a requirement that had previously been established as a key structural feature [26,27]. The presence of a blue contour near the carbon atoms in the side chain of fluorinated compounds (15a and 18a) indicates that use of electronegative groups is better than use of electropositive groups. However, some studies have shown activity in analogues without substituents on the chain, with shorter side chains or even analogues without side chain [28-32]. 
Figure $4 \mathrm{c}$ shows the distribution of hydrogen-bond acceptor field. Magenta and red contour maps represent favorable and unfavorable positions for hydrogen-bond acceptor groups. Two magenta isopleths around the hydroxyl groups at C-2 and C-23 positions suggest that the presence of hydrogen-bond acceptor group at those positions might enhance the activity. On the other hand, two red contours are sighted in the proximity of the hydroxyl group at C-3 position, which suggests that it would be more appropriate to functionalize with H-bond acceptor groups. This is consistent with the blue isopleth at the same position in the electrostatic contour map. Another two red isopleths were found in the hydrogen-bond acceptor contour map, one surrounding the carbonyl group at B-ring and the other in the hydroxyl group at C-20 position indicating that $\mathrm{H}$-bond acceptor group at this position may be unfavorable. Compounds $25 \mathrm{a}$ and $\mathbf{2 6 a}$, which contain an $\mathrm{OH}$ group at $\mathrm{C}-20$ position are less active, while compounds hydroxylated at C-17 position (16a and 21a) do not have this restriction, and have better activity.

\subsubsection{Model B}

Figure $5 c-e$ present the CoMSIA-EHA contour maps that illustrates the electrostatic, hydrophobic, and hydrogen-bond acceptor fields around compound $\mathbf{6 a}$ as reference structure.

As shown in Figure 5c, CoMSIA electrostatic (blue favored 85\%, and red disfavored 20\%) contour map was comparatively similar to the electrostatic contour maps of CoMFA model A and CoMSIA model A. Since this field was already explained, this will not be explained here again. The hydrophobic field effect is shown in Figure $5 \mathrm{~d}$, the presence of the yellow and white color ( $80 \%$ and $20 \%$ contributions) contour maps explain the favorable and unfavorable influence of the hydrophobic fields, respectively. A big yellow contour is sighted with clear predominance throughout the structure showing projections towards the side chain and at the 3rd position of the brassinolide (6a). Therefore, these positions appear to be optimal for modulating lipophilicity of the compounds indicating that hydrophobic groups at those positions would be favorable. This information is consistent with reports that BRs are lipophilic compounds, characterized by a $5 \alpha$-cholestane skeleton, oxygenated at least at C-3, C-22 and C-23 [33].

Figure 5 e shows the contour map for hydrogen-bond acceptor field (magenta-favored $80 \%$ and red disfavored 20\%). A magenta isopleth around the $\alpha$-oriented hydroxyl groups at C-2 and C-3 positions, and one big red contour surrounding the 3 rd position suggest that possible polyhydroxylations in A-ring would be favorable, with an alpha substitution pattern in both positions, as already was discussed while describing the CoMFA electrostatic contour map for model A. Another magenta contour appeared at C-17 position, indicating that substituents containing hydrogen-bond acceptor group directly attached to D-ring might enhance the activity. This can be explained by the fact that compounds having hydroxyl directly attached at C-17 are among the most active of the series $(16 b, 18 b, 20 b, 21 b, 25 b, 26 b$, and 21a).

\subsubsection{SAR Summary}

In order to systematize the main structural-activity relationships found and discussed in this study, Figure 6 presents the main modifications that can be explored on the brassinosteroid system. The areas that can be modified are in rings A, B, and in the chain at position 17. 


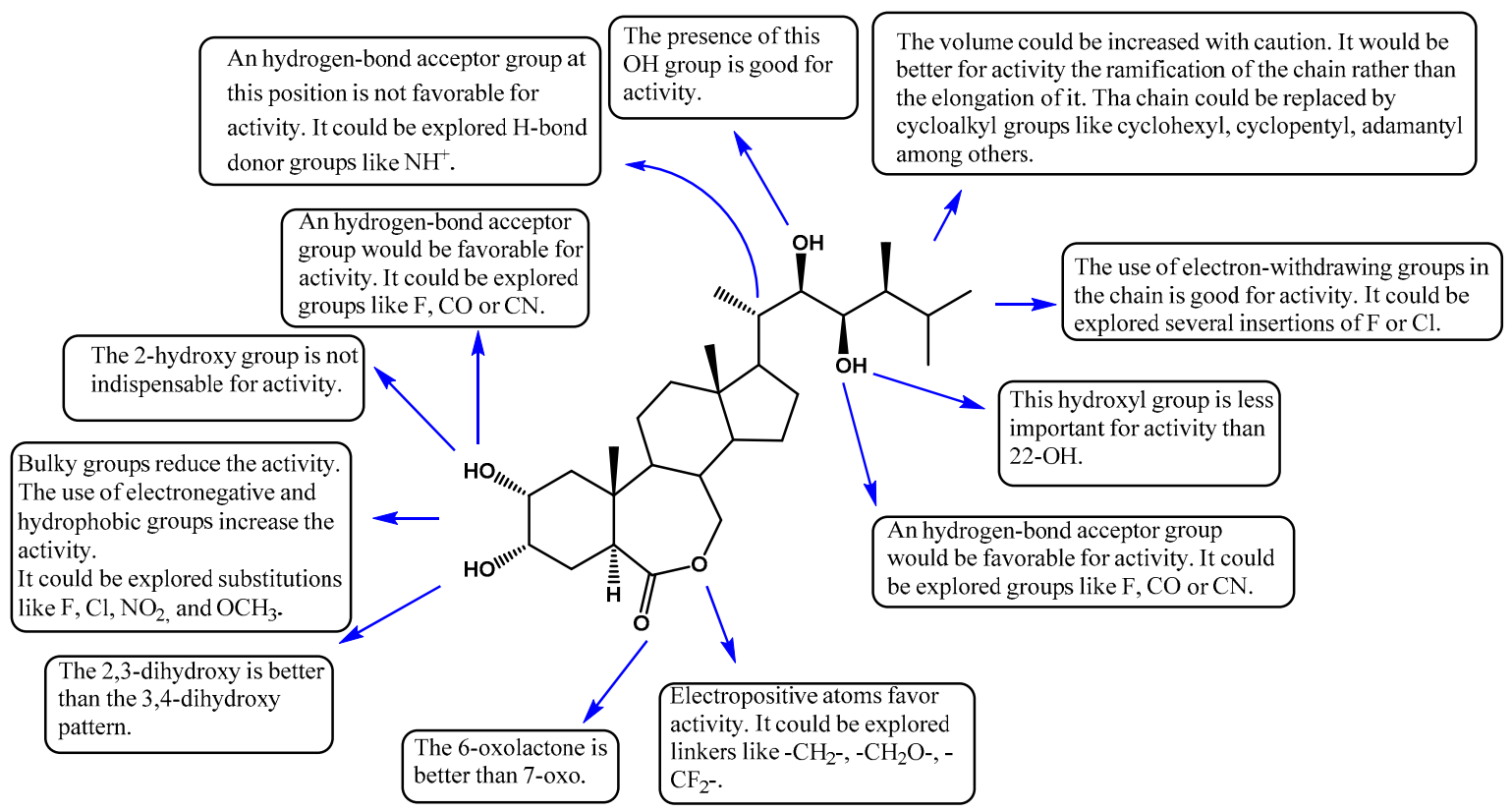

Figure 6. Summary of the main SAR discussed and found in this study.

\section{Materials and Methods}

\subsection{Data Sets Selection and Biological Activity}

A set of 27 molecules with biological activity tested at $10^{-9} \mathrm{M}$ (Model A) and a set of 38 molecules with biological activity tested at $10^{-10} \mathrm{M}$ (Model B) were selected from available literature [3,28-30,34,35]. In both models, the bean second-internode bioassay was used as biological activity for the generation of the 3D-QSAR models (CoMFA and CoMSIA). The biological activity of the data set compounds was reported as E value (elongation, in millimeters), which spanned across a wide range 2.50-38.50 mm for Model A and $0.80-54.80 \mathrm{~mm}$ for Model B. The $\mathrm{E}$ values were converted into $\mathrm{pE}$ values using the formula $\log (100 \times \mathrm{E} / \mathrm{Emax})$. The training and test sets were randomly chosen in 8:2 ratio. Both sets contain compounds with varied biological activities and various structural modifications. This allows guaranteeing an adequate predictive capacity of the models. The chemical structures of all molecules, along with their $\mathrm{E}$ and $\mathrm{pE}$ values, are shown in Tables 7 and 8.

Table 7. Chemical structures of brassinosteroid analogues of Model A $\left(10^{-9} \mathrm{M}\right)$ with their actual activity.

No. Compound


Table 7. Cont.

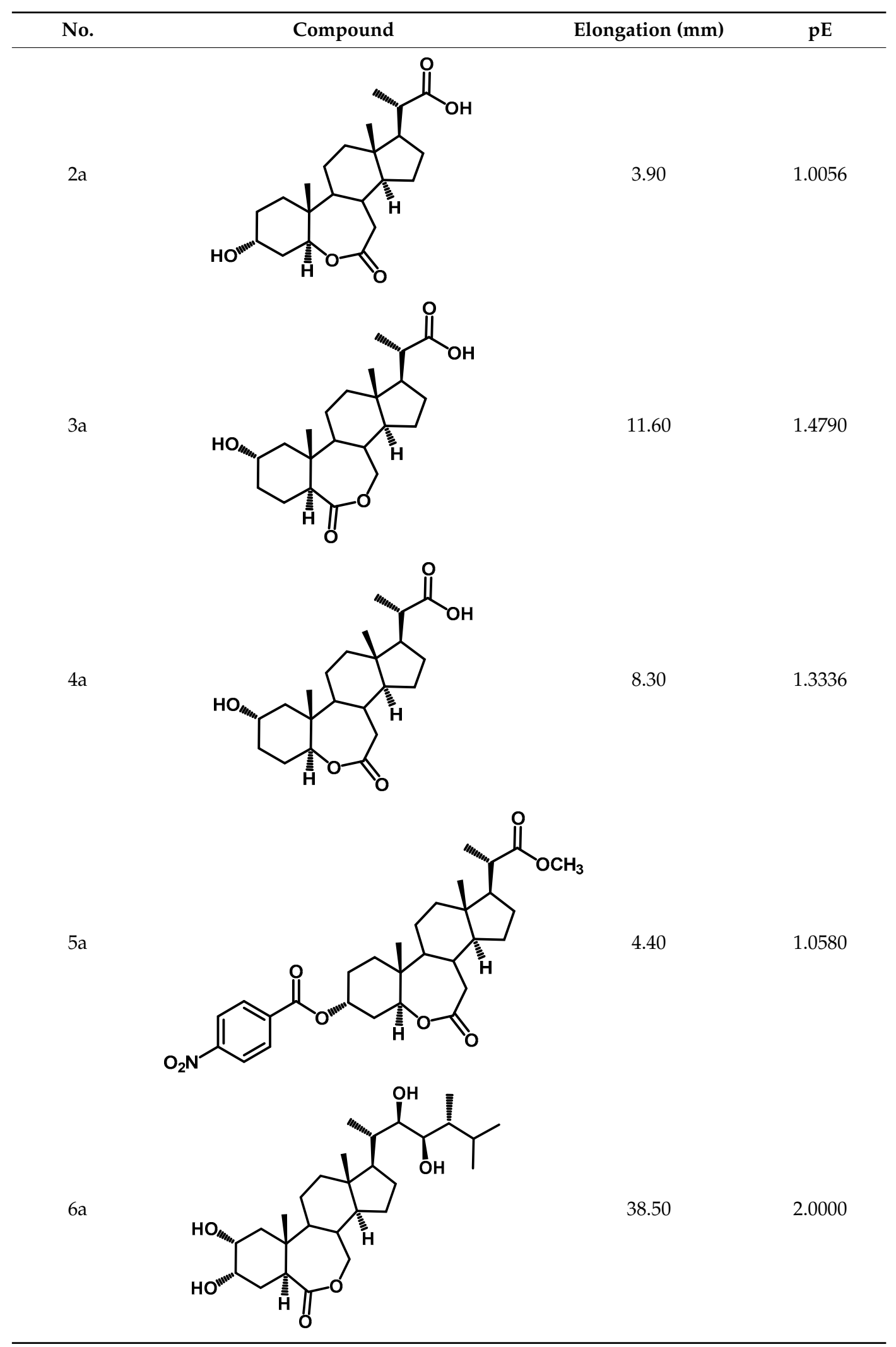


Table 7. Cont.

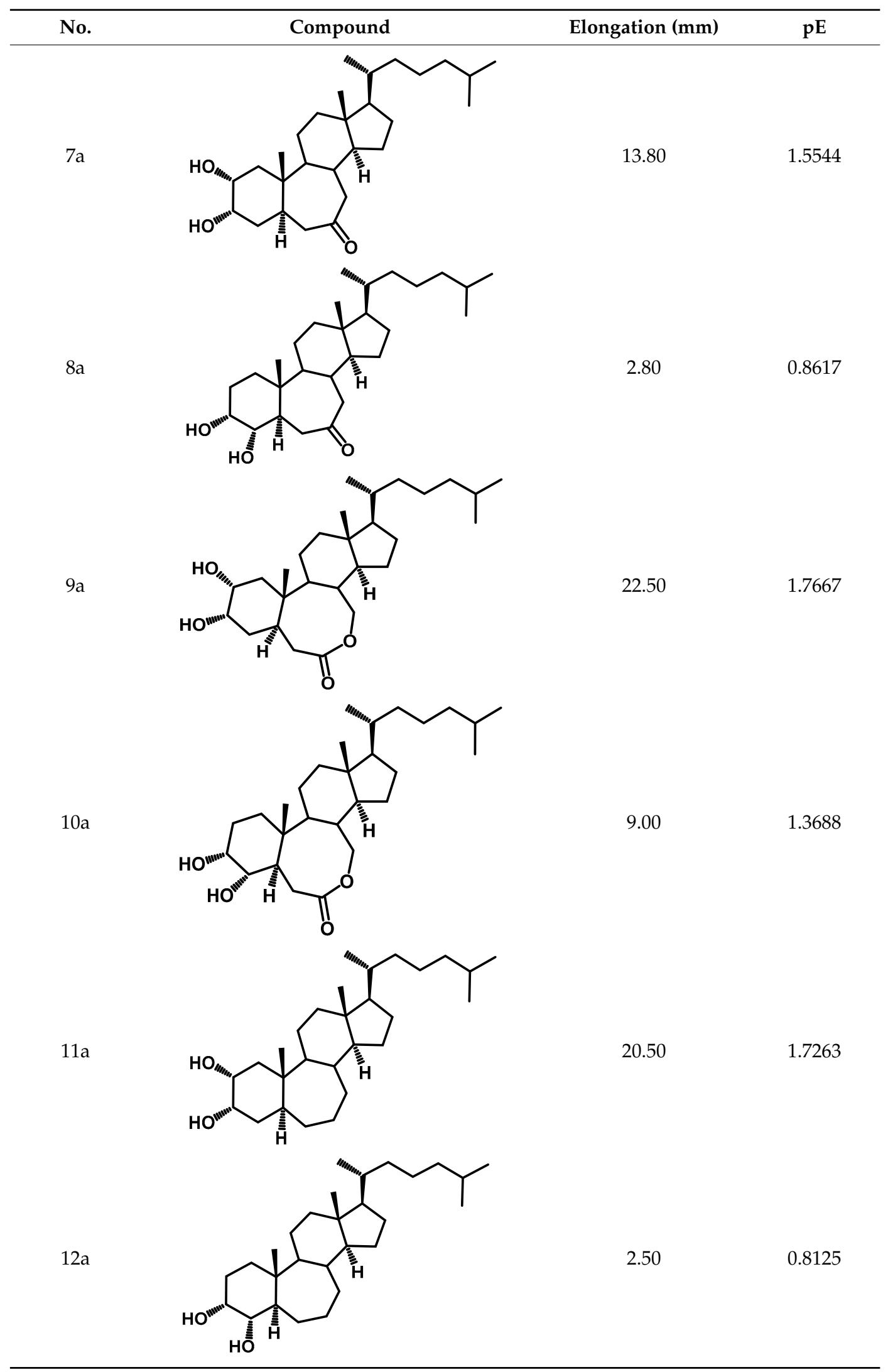


Table 7. Cont.

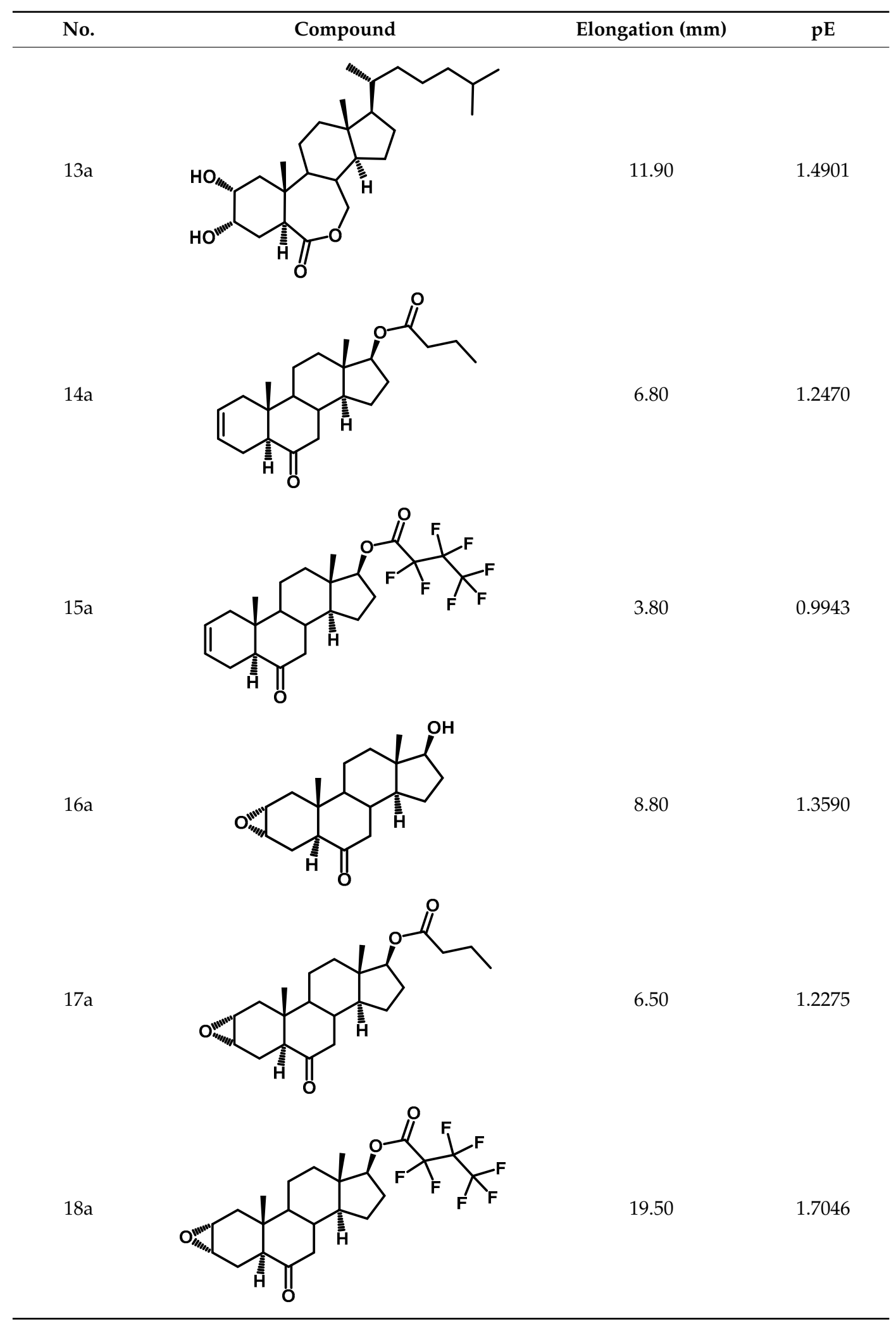


Table 7. Cont.

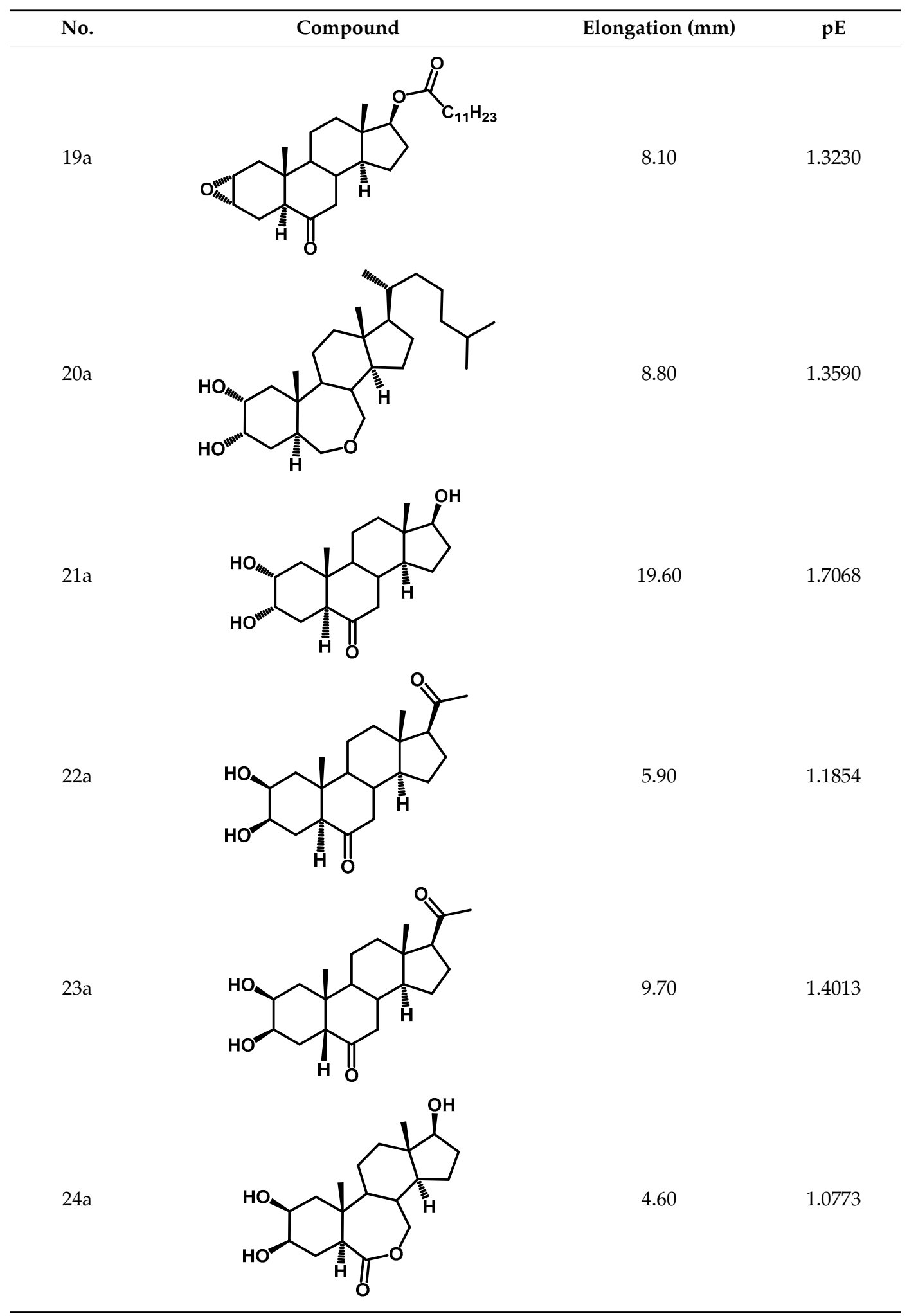


Table 7. Cont.

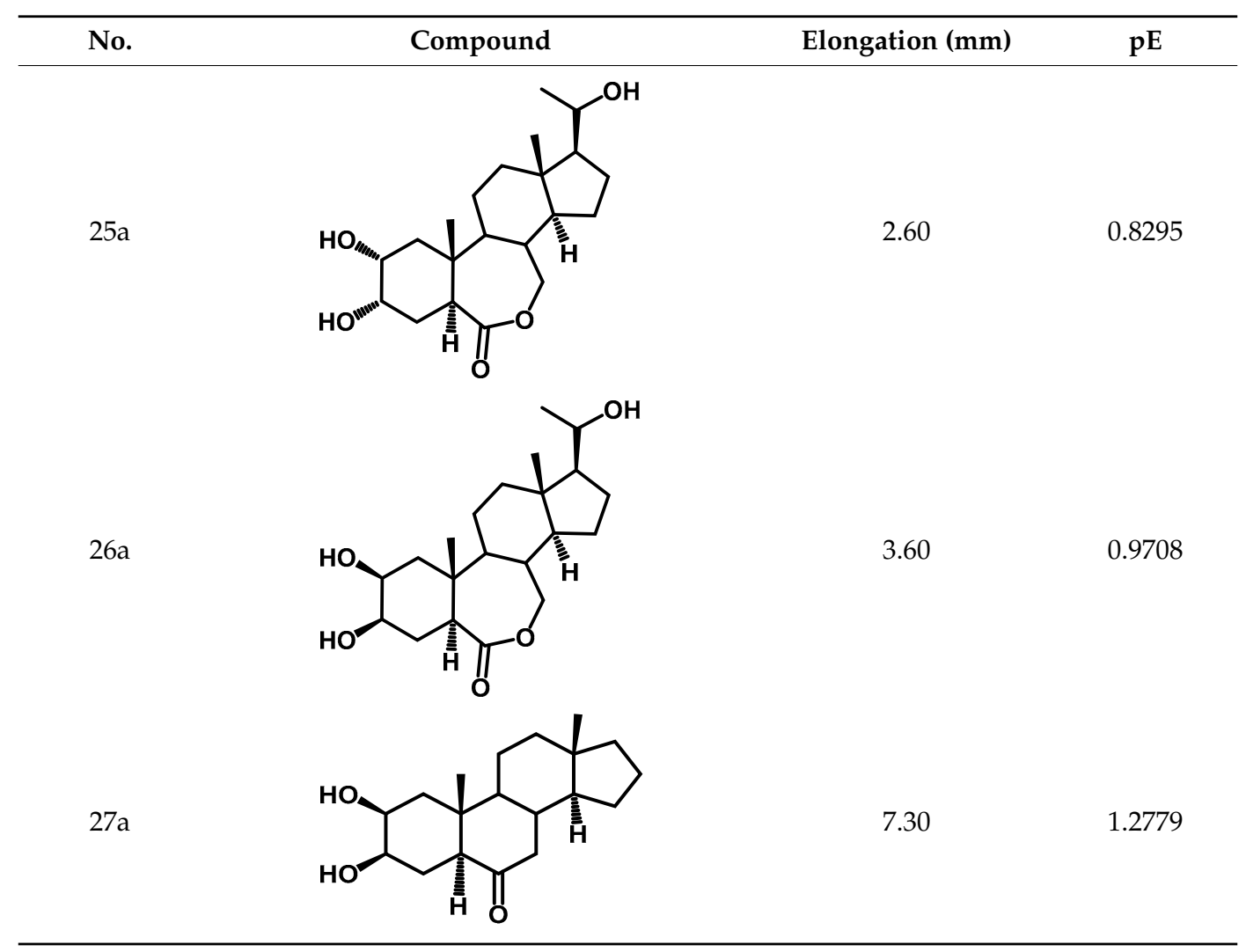

Table 8. Chemical structures of brassinosteroid analogues of model B $\left(10^{-10} \mathrm{M}\right)$ with their actual activity.

No. Elongation (mm)


Table 8. Cont.

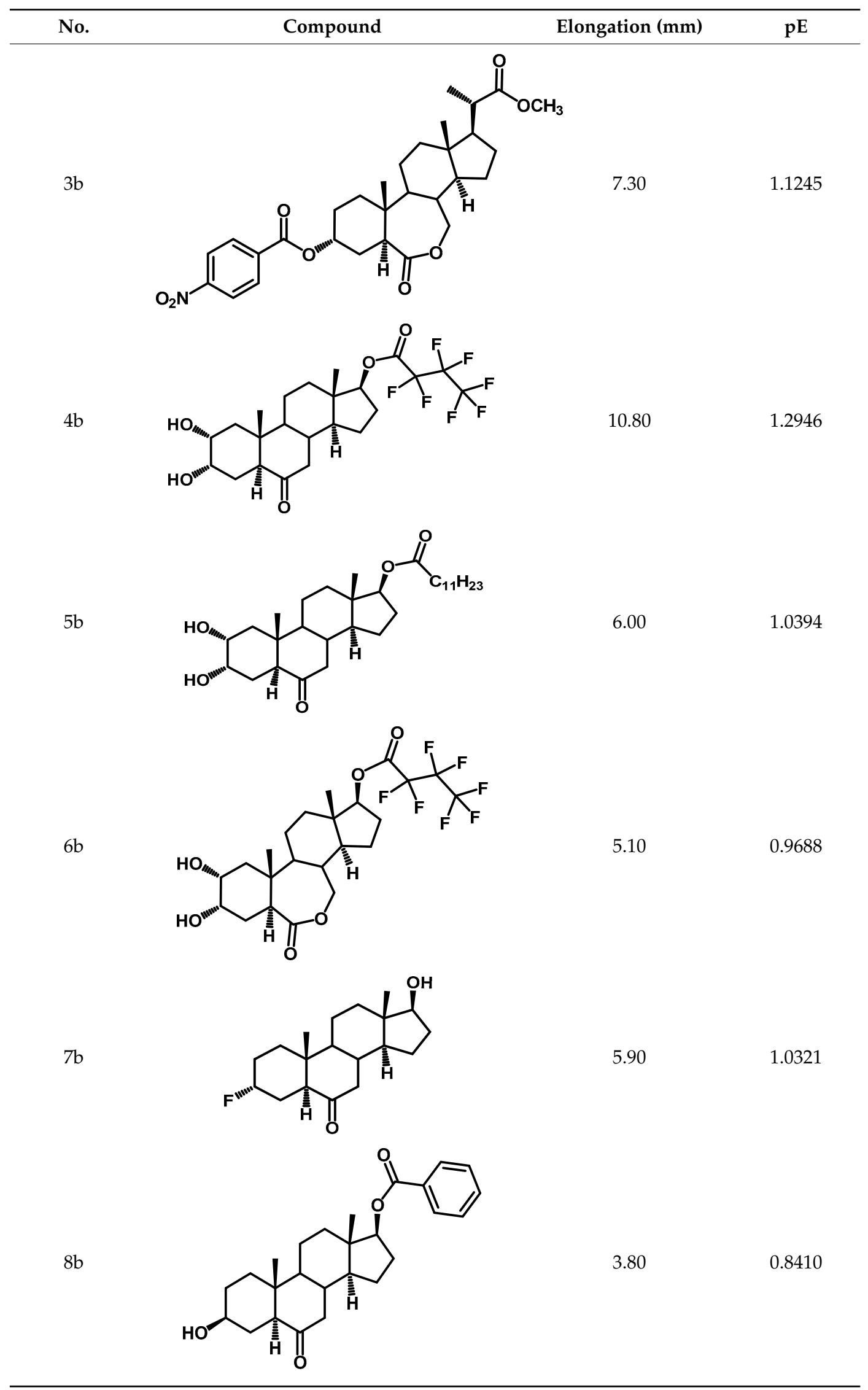


Table 8. Cont.

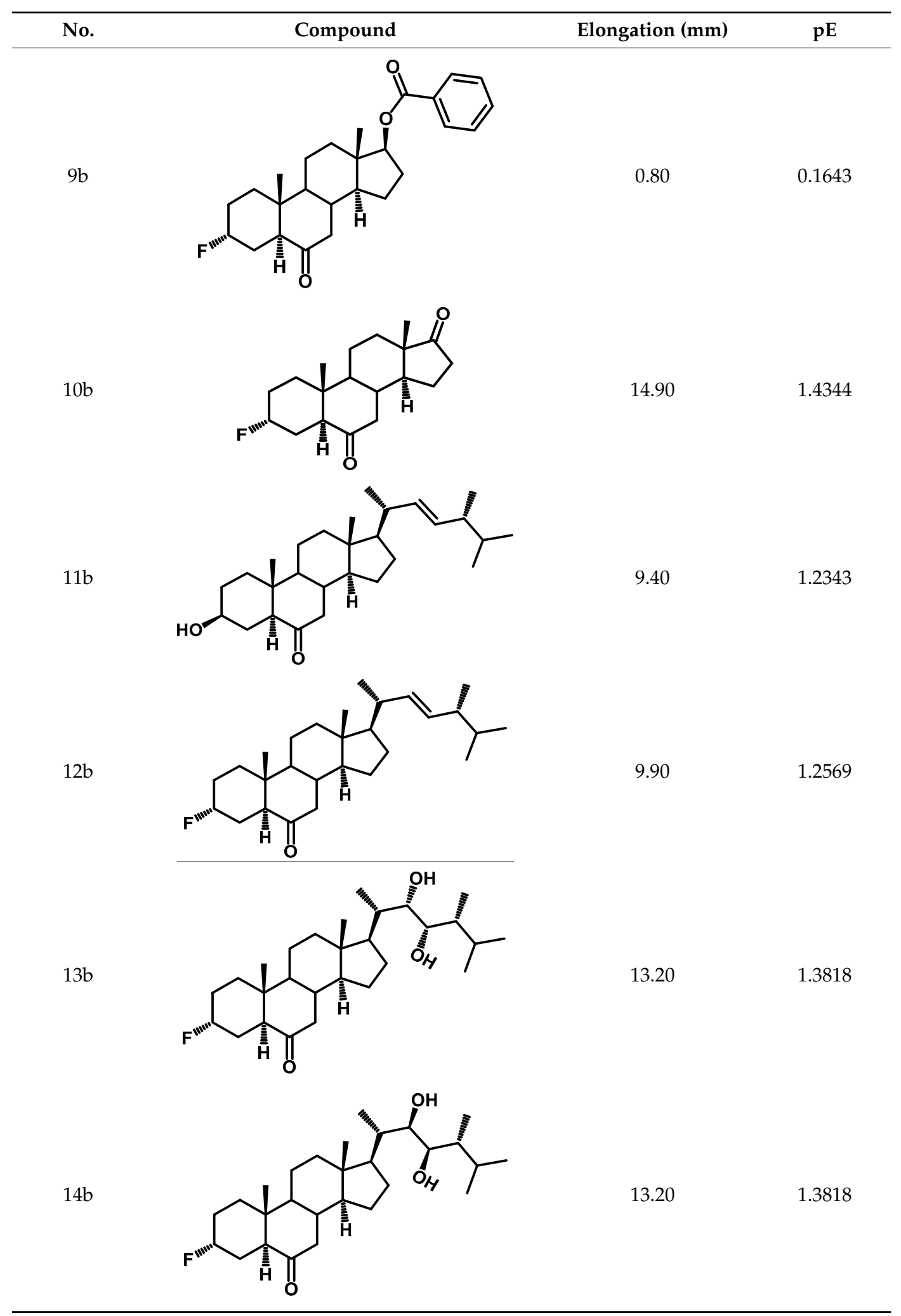


Table 8. Cont.

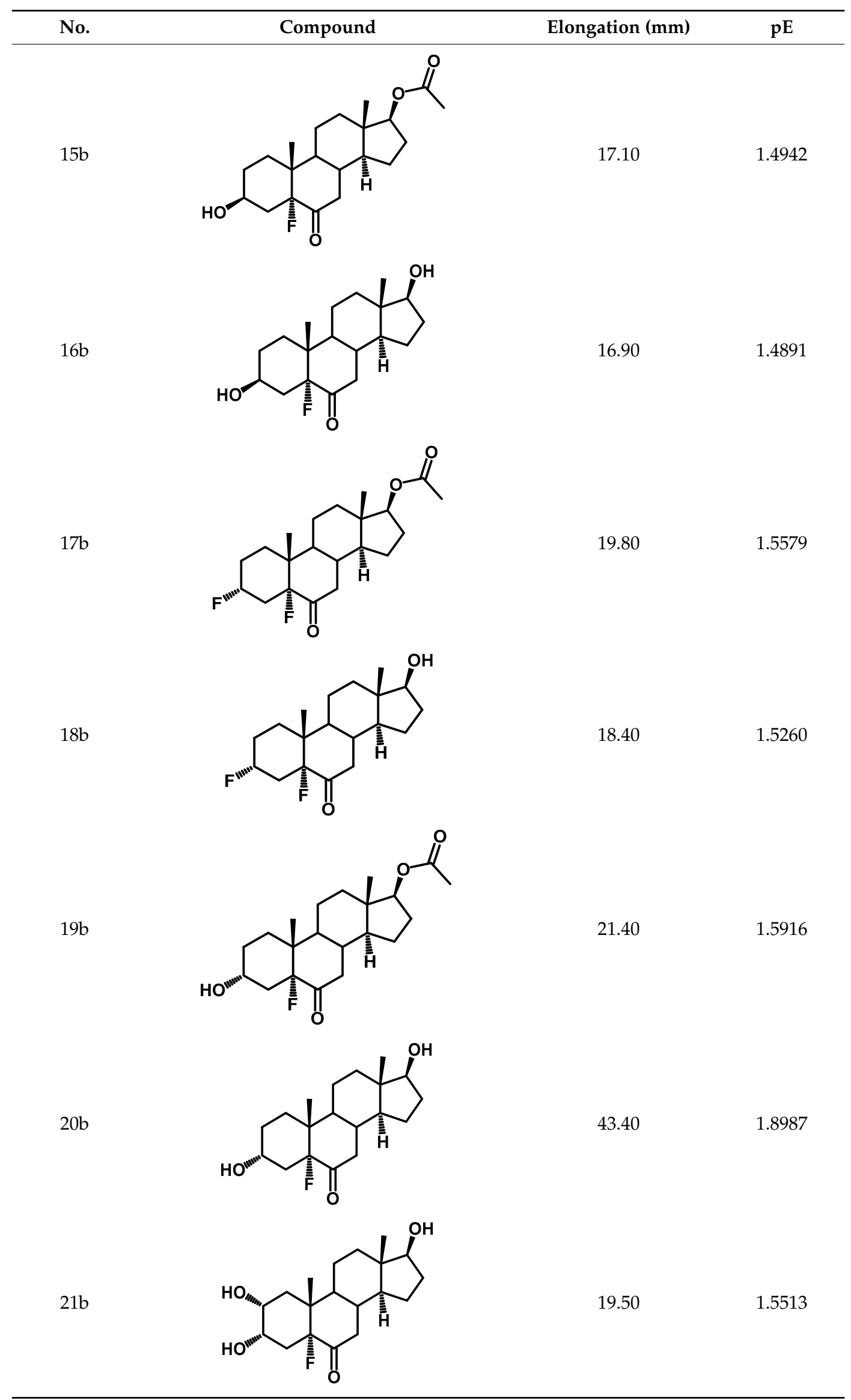


Table 8. Cont.

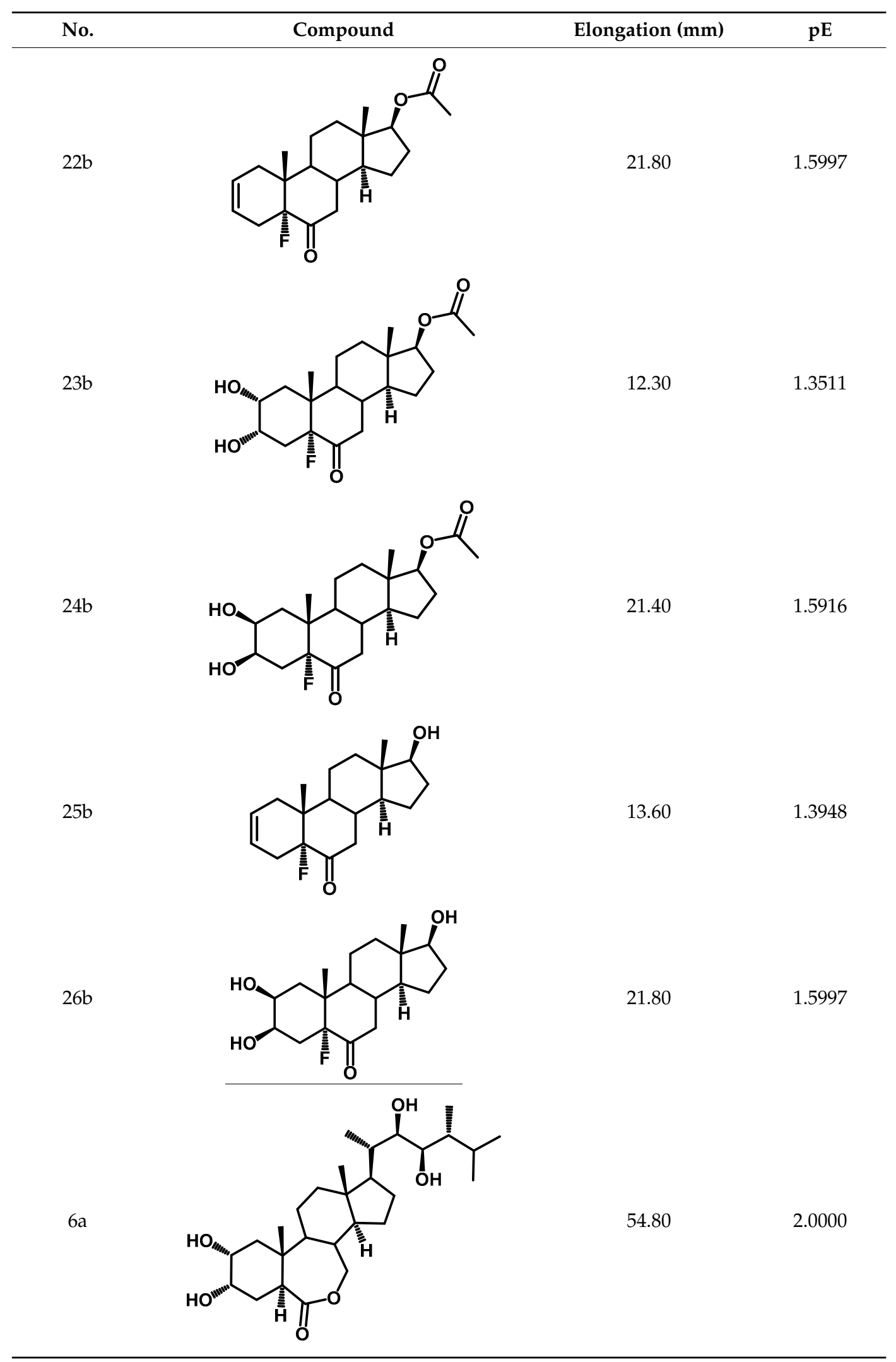


Table 8. Cont.

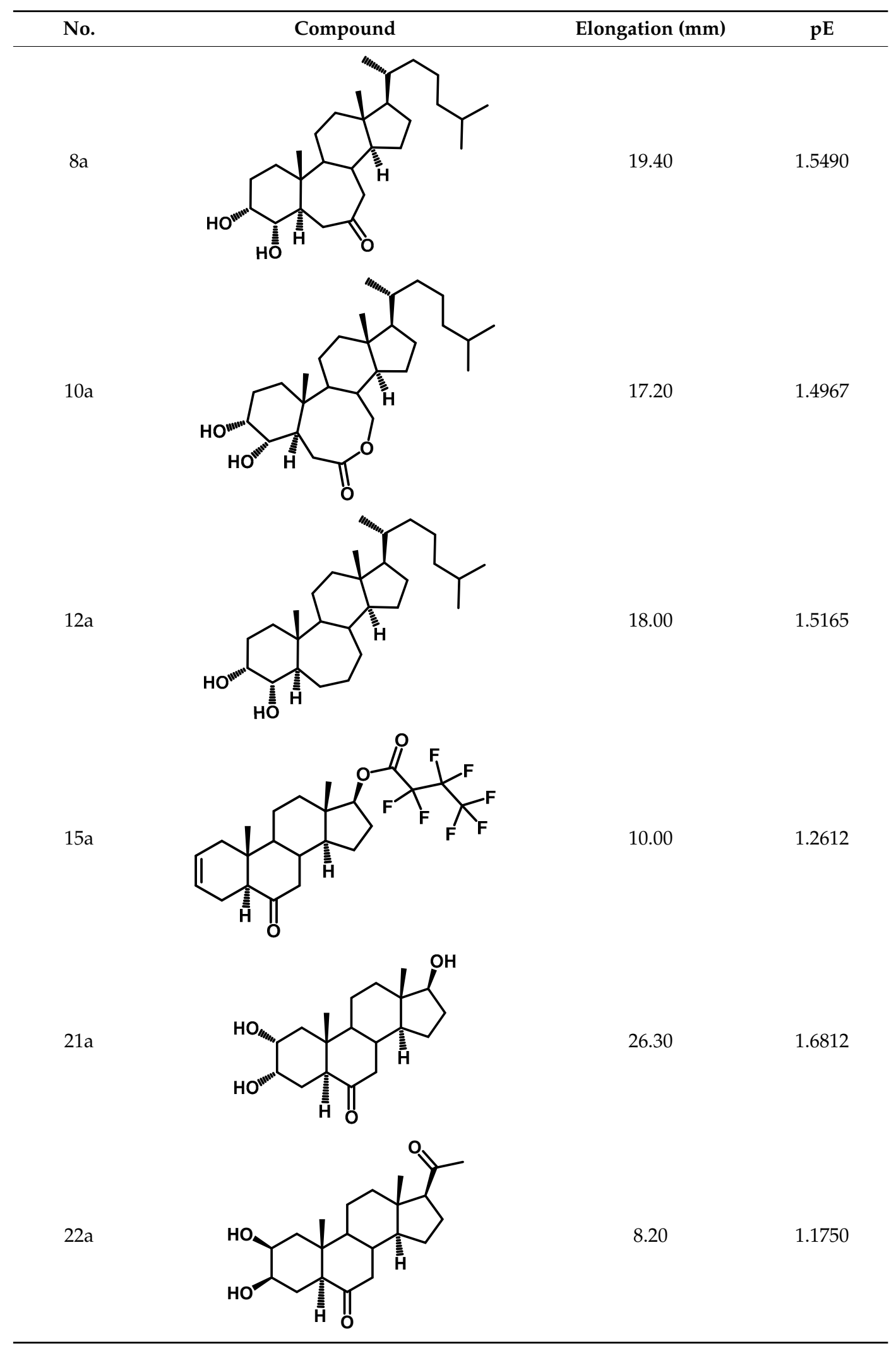


Table 8. Cont.

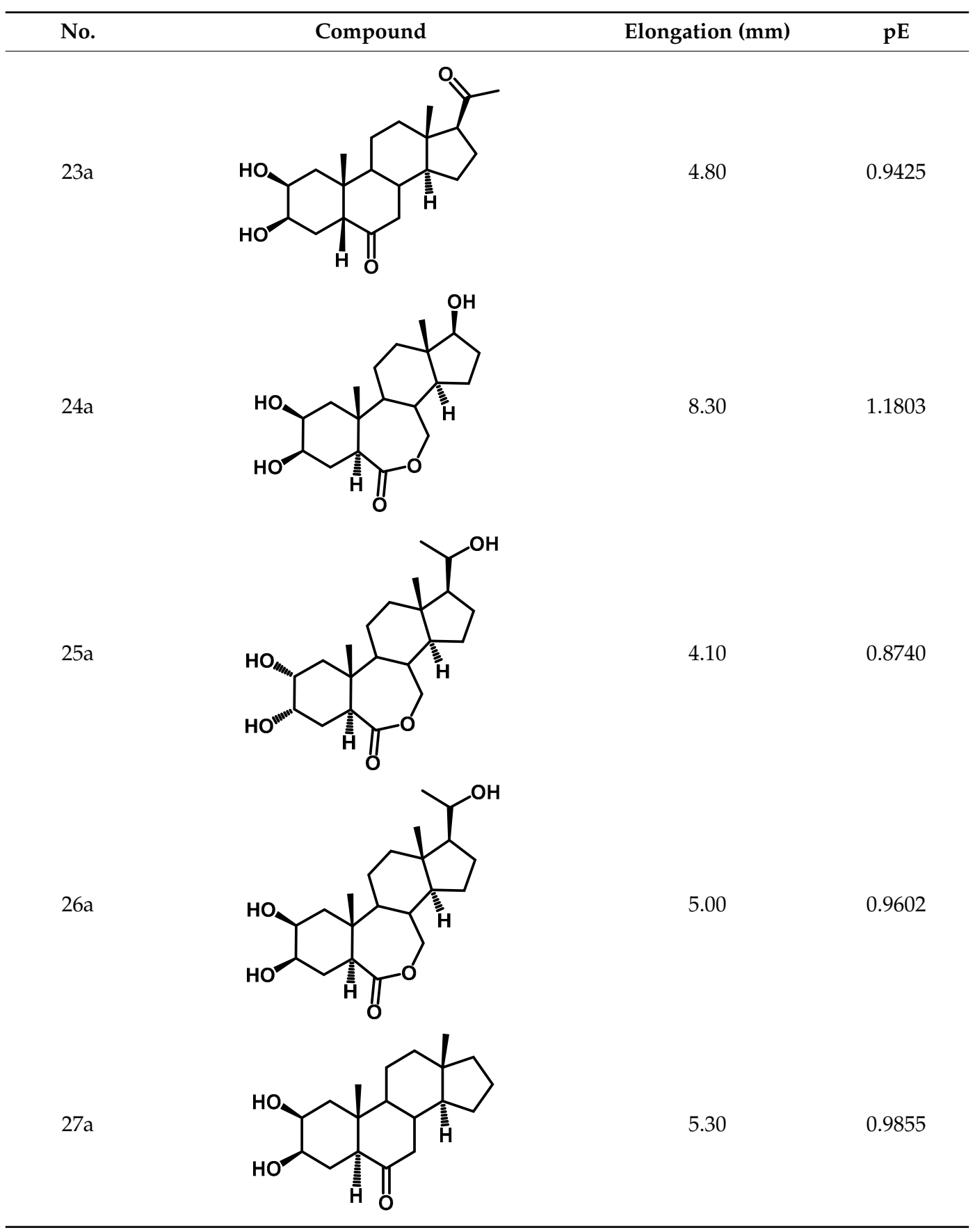

\subsection{Molecular Alignment}

The entire study was carried out in the Sybyl X software [36]. Each structure was previously minimized by the Tripos force field (1000 iterations) [37]. The term gradient was adjusted to $0.005 \mathrm{Kcal} / \mathrm{mol} \cdot \AA$. The calculation of atomic charges for each structure was carried out using the Gaisteiger-Hückel method [38]. Each minimized structure was then subjected to simulated annealing dynamics. The structures were heated to $1000 \mathrm{~K}$ per 1000 femtoseconds (fs), and then cooled to $50 \mathrm{~K}$ per $1000 \mathrm{fs}$. The best final conformers were selected for the construction of the final CoMFA and CoMSIA models. The database thus obtained was aligned using distill rigid alignment protocol. 


\subsection{CoMFA and CoMSIA Field Calculation}

The aligned database was positioned in the center of a cubic lattice with a grid spacing of $2 \AA$. A carbon atom with charge +1 and an atomic radius of $1.52 \AA$ was used as a probe to calculate the potentials. The energy cut-off value was set by default at $30 \mathrm{Kcal} / \mathrm{mol}$. To reduce noise and speed up the calculation of potentials, the column filtering value was set to $2.0 \mathrm{Kcal} / \mathrm{mol}$. In the case of CoMSIA, for the calculation of hydrophobic and hydrogen-bond potentials, a probe atom with hydrophobicity +1 and HBD/HBA of +1 was used. The attenuation factor $\alpha$ was set by default at 0.3 [39].

\subsection{Internal Validation and Partial Least Squares (PLS) Analysis}

The search for a correlation between biological activity (dependent variable) and calculated potentials (independent variables) for CoMFA and CoMSIA was carried out by means of PLS statistical analysis. Regression analysis was performed through leave-one-out (LOO) cross-validation procedure using SAMPLS method [40].

In CoMFA and CoMSIA, the cross-validation analysis was applied to determine the value of the cross-validation coefficient $\left(q^{2}\right)$, the cross-validated standard error of predictions (SEP), and the optimal number of components $(\mathrm{N})$. The $\mathrm{q}^{2}$ value is a measure of the internal quality of the models which was calculated using the following formula:

$$
\mathrm{q}^{2}=1-\frac{\sum\left(\mathrm{y}_{\mathrm{i}}-\mathrm{y}_{\text {pred }}\right)^{2}}{\sum\left(\mathrm{y}_{\mathrm{i}}-\overline{\mathrm{y}}\right)^{2}}
$$

where $\mathrm{y}_{\mathrm{i}}, \overline{\mathrm{y}}$, and $\mathrm{y}_{\text {pred }}$ are the observed, mean, and predicted activity in the training set, respectively.

Final non-cross validated conventional analysis [41] was generated with the optimal number of components equal to that yielding the highest $\mathrm{q}^{2}$, and the corresponding conventional correlation coefficient $\mathrm{r}_{\text {ncv }}^{2}$ was obtained.

In addition, the statistical significance of the models was described by its standard error of estimate (SEE) and the probability value ( $F$-value).

\subsection{D-QSAR External Validation}

The external predictive capacity of each built model was evaluated by calculating the predictive correlation coefficient $\left(\mathrm{r}^{2}\right.$ pred $)[42,43]$, which was obtained from the following equation:

$$
\mathrm{r}_{\text {pred }}^{2}=\frac{\mathrm{SD}-\mathrm{PRESS}}{\mathrm{SD}}
$$

where $\mathrm{SD}$ is the sum of squared deviations between the biological activities of the test set molecules, and the mean activities of the training molecules and PRESS is the sum of squared deviations between actual and predicted activity values for each molecule in the test set [44,45]. For a predictive QSAR model, the value of $\mathrm{r}^{2}$ pred should be more than 0.6.

Moreover, the models were also subjected to external validation criteria according to the proposed test by Golbraikh and Tropsha [22]. The external predictive power of the developed QSAR models using the test set was examined by considering $r_{m}^{2}$ metrics, as shown below [46]:

$$
\mathrm{r}_{\mathrm{m}}^{2}=\mathrm{r}^{2}\left(1-\sqrt{\mathrm{r}^{2}-\mathrm{r}_{0}^{2}}\right)
$$

where $\mathrm{r}^{2}$ and $\mathrm{r}_{0}^{2}$ are squared correlation coefficients between the observed and predicted activities of the test set with and without intercept, respectively. For a significant external model validation, the value of $\mathrm{r}_{\mathrm{m}}^{2}$ should be more than 0.5 . 
Tropsha et al. [47] considered a QSAR model predictive, if the following conditions are satisfied:

$$
\begin{gathered}
\mathrm{q}^{2}>0.5 \\
\mathrm{r}^{2}>0.6 \\
\frac{\left(\mathrm{r}^{2}-\mathrm{r}_{0}^{2}\right)}{\mathrm{r}^{2}}<0.1 \text { or } \frac{\left(\mathrm{r}^{2}-\mathrm{r}_{0}^{\prime 2}\right)}{\mathrm{r}^{2}}<0.1 \\
0.85 \leq \mathrm{k} \leq 1.15 \text { or } 0.85 \leq \mathrm{k}^{\prime} \leq 1.15
\end{gathered}
$$

It has been demonstrated [22] that all of the above criteria are indeed necessary to adequately assess the predictive ability of a QSAR model.

\section{Conclusions}

Brassinosteroid analogues previously reported in literature have been studied by using 3D-QSAR analysis. CoMFA and CoMSIA approaches were carried out to determine structural requirements for improving potency of brassinosteroid analogues as plant-growth promoters using the bean second-internode bioassay. Overall, the statistical results of both models studied at different molar concentrations exhibited good correlation, good predictive power and satisfactory agreement with previous literature reports. The 3D contour maps showed that the growth promoting activity of the compounds was influenced mainly by electrostatic properties and the presence of hydrogen-bond acceptor groups. The information obtained in this study provides useful suggestions that can be used in the successful design, development and synthesis of novel derivatives. The actual synthesis of new derivatives is on-going and will later be screened for its biological activity.

Acknowledgments: Authors would like to thank the Chilean National Science and Technology Research Fund FONDECYT (11130701 and 1160446), National Commission for Scientific and Technological Research CONICYT (Doctoral Fellowship N²1170877) and Universidad Técnica Federico Santa María (PIIC N 051/2015) for the financial support.

Author Contributions: Karoll Ferrer-Pertuz perform the LOO, contour maps analysis and wrote the paper. Luis Espinoza and Jaime Mella conducted the study.

Conflicts of Interest: The authors declare no conflict of interest.

\section{Abbreviations}

$\begin{array}{ll}\text { 3D-QSAR } & \text { Three-Dimensional Quantitative Structure-Activity Relationship } \\ \text { CoMFA } & \text { Comparative Molecular Field Analysis } \\ \text { CoMSIA } & \text { Comparative Molecular Similarity Index Analysis } \\ \text { PLS } & \text { Partial Least Squares } \\ \text { LOO } & \text { Leave-One-Out } \\ \mathrm{N} & \text { Optimal Number of Components } \\ \mathrm{r}_{\mathrm{ncv}}{ }^{2} & \text { Non-Cross Validation Coefficient } \\ \mathrm{q}^{2} & \text { Cross Validation Coefficient } \\ \mathrm{r}^{2} \text { pred } & \text { Predictive Correlation Coefficient } \\ F & \text { Fischer-Test Value } \\ \text { SEE } & \text { Standard Error of Estimation } \\ \text { SEP } & \text { Standard Error of Prediction }\end{array}$




\section{References}

1. Vert, G.; Nemhauser, J.L.; Geldner, N.; Hong, F.; Chory, J. Molecular mechanisms of steroid hormone signaling in plants. Annu. Rev. Cell Dev. Biol. 2005, 21, 177-201. [CrossRef] [PubMed]

2. Izumi, Y.; Okazawa, A.; Bamba, T.; Kobayashi, A.; Fukusaki, E. Development of a method for comprehensive and quantitative analysis of plant hormones by highly sensitive nanoflow liquid chromatography-electrospray ionization-ion trap mass spectrometry. Anal. Chim. Acta 2009, 648, 215-225. [CrossRef] [PubMed]

3. Kvasnica, M.; Oklestkova, J.; Bazgier, V.; Rarova, L.; Berka, K.; Strnad, M. Biological activities of new monohydroxylated brassinosteroid analogues with a carboxylic group in the side chain. Steroids 2014, 85, 58-64. [CrossRef] [PubMed]

4. Bajguz, A.; Tretyn, A. The chemical characteristic and distribution of brassinosteroids in plants. Phytochemistry 2003, 62, 1027-1046. [CrossRef]

5. Bajguz, A.; Tretyn, A. The Chemical Structures and Occurrence of Brassinosteroids in Plants. In Brassinosteroids; Springer: Dordrecht, The Netherlands, 2003; pp. 1-44.

6. Serna, M.; Hernández, F.; Coll, F.; Amorós, A. Brassinosteroid analogues effect on yield and quality parameters of field-grown lettuce (Lactuca sativa L.). Sci. Hortic. (Amsterdam) 2012, 143, 29-37. [CrossRef]

7. Acebedo, S.L.; Alonso, F.; Ramírez, J.A.; Galagovsky, L.R. Synthesis of aromatic stigmastanes: Application to the synthesis of aromatic analogs of brassinosteroids. Tetrahedron 2012, 68, 3685-3691. [CrossRef]

8. Krishna, P. Brassinosteroid-mediated stress responses. J. Plant Growth Regul. 2003, 22, 289-927. [CrossRef] [PubMed]

9. Bajguz, A.; Piotrowska-Niczyporuk, A. Brassinosteroids Implicated in Growth and Stress Responses. In Phytohormones: A Window to Metabolism, Signaling and Biotechnological Applications; Springer: New York, NY, USA, 2014; pp. 163-190.

10. Kim, T.-W.; Lee, S.M.; Joo, S.-H.; Yun, H.S.; Lee, Y.; Kaufman, P.B.; Kirakosyan, A.; Kim, S.-H.; Nam, K.H.; Lee, J.S.; et al. Elongation and gravitropic responses of Arabidopsis roots are regulated by brassinolide and IAA. Plant Cell Environ. 2007, 30, 679-689. [CrossRef] [PubMed]

11. Wang, Q.; Xu, J.; Liu, X.; Gong, W.; Zhang, C. Synthesis of brassinosteroids analogues from laxogenin and their plant growth promotion. Nat. Prod. Res. 2015, 29, 149-157. [CrossRef] [PubMed]

12. Vlašánková, E.; Kohout, L.; Klemš, M.; Eder, J.; Reinöhl, V.; Hradilík, J. Evaluation of biological activity of new synthetic brassinolide analogs. Acta Physiol. Plant. 2009, 31, 987-993. [CrossRef]

13. Seto, H.; Hiranuma, S.; Fujioka, S.; Koshino, H.; Suenaga, T.; Yoshida, S. Preparation, conformational analysis, and biological evaluation of 6a-carbabrassinolide and related compounds. Tetrahedron 2002, 58, 9741-9749. [CrossRef]

14. Back, T.G.; Pharis, R.P. Structure-activity studies of brassinosteroids and the search for novel analogues and mimetics with improved bioactivity. J. Plant Growth Regul. 2003, 22, 350-361. [CrossRef] [PubMed]

15. Takatsuto, S.; Ikekawa, N.; Morishita, T.; Abe, H. Structure-activity relationship of brassinosteroids with respect to the A/B-ring functional groups. Chem. Pharm. Bull. (Tokyo) 1987, 35, 211-216. [CrossRef]

16. Brosa, C.; Capdevila, J.M.; Zamora, I. Brassinosteroids: A new way to define the structural requirements. Tetrahedron 1996, 52, 2435-2448. [CrossRef]

17. Brosa, C.; Zamora, I.; Terricabras, E.; Soca, L.; Peracaula, R.; Rodríguez-Santamarta, C. Synthesis and molecular modeling: Related approaches to progress in brassinosteroid research. Lipids 1997, 32, 1341-1347. [CrossRef] [PubMed]

18. Brosa, C.; Soca, L.; Terricabras, E.; Ferrer, J.C.; Alsina, A. New synthetic brassinosteroids: A 5 $\alpha$-hydroxy-6-ketone analog with strong plant growth promoting activity. Tetrahedron 1998, 54, 12337-12348. [CrossRef]

19. Brosa, C.; Zamora, I.; Terricabras, E.; Kohout, L. The Effect of electrostatic properties and abibility to form hydrogen-bonds on the activity of brassinosteroid side-chain analogs. Collect. Czechoslov. Chem. Commun. 1998, 63, 1635-1645. [CrossRef]

20. Hothorn, M.; Belkhadir, Y.; Dreux, M.; Dabi, T.; Noel, J.P.; Wilson, I.A.; Chory, J. Structural basis of steroid hormone perception by the receptor kinase BRI1. Nature 2011, 474, 467-471. [CrossRef] [PubMed]

21. She, J.; Han, Z.; Kim, T.-W.; Wang, J.; Cheng, W.; Chang, J.; Shi, S.; Wang, J.; Yang, M.; Wang, Z.-Y.; et al. Structural insight into brassinosteroid perception by BRI1. Nature 2011, 474, 472-476. [CrossRef] [PubMed]

22. Golbraikh, A.; Tropsha, A. Beware of q2! J. Mol. Graph. Model. 2002, 20, 269-276. [CrossRef] 
23. Pereira-Netto, A.B.; Schaefer, S.; Galagovsky, L.R.; Ramirez, J.A. Brassinosteroid-Driven Modulation of Stem Elongation and Apical Dominance: Applications in Micropropagation. In Brassinosteroids; Hayat, S., Ahmad, A., Eds.; Springer: Dordrecht, The Netherlands, 2003; pp. 129-157.

24. Baron, D.L.; Luo, W.; Janzen, L.; Pharis, R.P.; Back, T.G. Structure-activity studies of brassinolide B-ring analogues. Phytochemistry 1998, 49, 1849-1858. [CrossRef]

25. Strnad, M.; Kohout, L. A simple brassinolide analogue $2 \alpha, 3 \alpha$-dihydroxy-17 $\beta$-(3-methyl-butyryloxy)-7-oxa-Bhomo-5 $\alpha$-androstan-6-one which induces bean second internode splitting. Plant Growth Regul. 2003, 40, 39-47. [CrossRef]

26. Thompson, M.J.; Meudt, W.J.; Mandava, N.B.; Dutky, S.R.; Lusby, W.R.; Spaulding, D.W. Synthesis of brassinosteroids and relationship of structure to plant growth-promoting effects. Steroids 1982, 39, 89-105. [CrossRef]

27. Takatsuto, S.; Yazawa, N.; Ikekawa, N.; Takematsu, T.; Takeuchi, Y.; Koguchi, M. Structure-activity relationship of brassinosteroids. Phytochemistry 1983, 22, 2437-2441. [CrossRef]

28. Šíša, M.; Vilaplana-Polo, M.; Ballesteros, C.B.; Kohout, L. Brassinolide activities of $2 \alpha, 3 \alpha$-diols versus $3 \alpha, 4 \alpha$-diols in the bean second internode bioassay: Explanation by molecular modeling methods. Steroids 2007, 72, 740-750. [CrossRef] [PubMed]

29. Šíša, M.; Buděšínský, M.; Kohout, L. Synthesis and biological activity of 7a-homo- and 7a,7b-dihomo-5 $\alpha-$ cholestane analogues of brassinolide. Collect. Czechoslov. Chem. Commun. 2003, 68, 2171-2189. [CrossRef]

30. Slavikova, B.; Kohout, L.; Budesinsky, M.; Swaczynova, J.; Kasal, A. Brassinosteroids: Synthesis and activity of some fluoro analogues. J. Med. Chem. 2008, 51, 3979-3984. [CrossRef] [PubMed]

31. Takatsuto, S.; Yazawa, N.; Ikekawa, N. Synthesis and biological activity of brassinolide analogues, 26,27-bisnorbrassinolide and its 6-oxo analogue. Phytochemistry 1984, 23, 525-528. [CrossRef]

32. Kohout, L.; Strnad, M. Brassinolide analogues without side chain. Collect. Czechoslov. Chem. Commun. 1989, 54, 1019-1027. [CrossRef]

33. Zullo, M.A.T.; de Azevedo, M.D.B.M. Brassinosteroids and Brassinosteroid Analogues Inclusion Complexes in Cyclodextrins. In Brassinosteroids; Hayat, S., Ahmad, A., Eds.; Springer: Dordrecht, The Netherlands, 2003; pp. 171-188.

34. Šíša, M.; Hniličková, J.; Swaczynová, J.; Kohout, L. Syntheses of new androstane brassinosteroids with $17 \beta$-ester groups-Butyrates, heptafluorobutyrates, and laurates. Steroids 2005, 70, 755-762. [CrossRef] [PubMed]

35. Kohout, L.; Velgová, H.; Strnad, M.; Kamínek, M. Brassino steroids with androstane and pregnane skeleton. Collect. Czechoslov. Chem. Commun. 1987, 52, 476-486. [CrossRef]

36. SYBYL-X 1.2. Tripos International, 1699 South Hanley Rd., St. Louis, Missouri, 63144, USA. 2011.

37. Vinter, J.G.; Davis, A.; Saunders, M.R. Strategic approaches to drug design. I. An integrated software framework for molecular modelling. J. Comput. Aided Mol. Des. 1987, 1, 31-51. [CrossRef] [PubMed]

38. Gasteiger, J.; Marsili, M. Iterative partial equalization of orbital electronegativity-A rapid access to atomic charges. Tetrahedron 1980, 36, 3219-3228. [CrossRef]

39. Klebe, G.; Abraham, U.; Mietzner, T. Molecular similarity indices in a comparative analysis (CoMSIA) of drug molecules to correlate and predict their biological activity. J. Med. Chem. 1994, 37, 4130-4146. [CrossRef] [PubMed]

40. Bush, B.L.; Nachbar, R.B. Sample-distance partial least squares: PLS optimized for many variables, with application to CoMFA. J. Comput. Aided Mol. Des. 1993, 7, 587-619. [CrossRef] [PubMed]

41. Clark, M.; Cramer, R.D. The probability of chance correlation using partial least squares (PLS). Quant. Struct. Relatsh. 1993, 12, 137-145. [CrossRef]

42. Oprea, T.I.; Waller, C.L.; Marshall, G.R. Three-dimensional quantitative structure-activity relationship of human immunodeficiency virus (I) protease inhibitors. 2. Predictive power using limited exploration of alternate binding modes. J. Med. Chem. 1994, 37, 2206-2215. [CrossRef] [PubMed]

43. Waller, C.L.; Oprea, T.I.; Giolitti, A.; Marshall, G.R. Three-dimensional QSAR of human immunodeficiency virus (I) protease inhibitors. 1. A CoMFA study employing experimentally-determined alignment rules. J. Med. Chem. 1993, 36, 4152-4160. [CrossRef] [PubMed]

44. Chang, T.-T.; Sun, M.-F.; Wong, Y.-H.; Yang, S.-C.; Chen, K.-C.; Chen, H.-Y.; Tsai, F.-J.; Chen, C.Y.-C. Drug design for mPGES-1 from traditional Chinese medicine database: A screening, docking, QSAR, molecular dynamics, and pharmacophore mapping study. J. Taiwan Inst. Chem. Eng. 2011, 42, 580-591. [CrossRef] 
45. Gupta, P.; Garg, P.; Roy, N. Comparative docking and CoMFA analysis of curcumine derivatives as HIV-1 integrase inhibitors. Mol. Divers. 2011, 15, 733-750. [CrossRef] [PubMed]

46. Roy, K.; Chakraborty, P.; Mitra, I.; Ojha, P.K.; Kar, S.; Das, R.N. Some case studies on application of " $r m^{2}$ " metrics for judging quality of quantitative structure-activity relationship predictions: Emphasis on scaling of response data. J. Comput. Chem. 2013, 34, 1071-1082. [CrossRef] [PubMed]

47. Tropsha, A. Best practices for QSAR model development, validation, and exploitation. Mol. Inform. 2010, 29, 476-488. [CrossRef] [PubMed]

2017 by the authors. Licensee MDPI, Basel, Switzerland. This article is an open access article distributed under the terms and conditions of the Creative Commons Attribution (CC BY) license (http://creativecommons.org/licenses/by/4.0/). 